
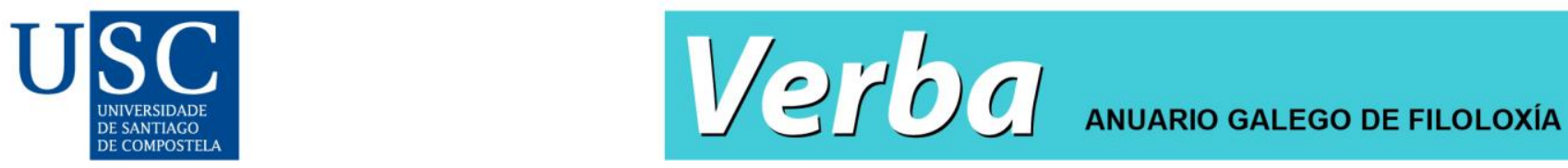

Verba: Anuario Galego de Filoloxía, 48, 2021. ISSN: 2174-4017

https://doi.org/10.15304/verba.48.6864

Artículos

\title{
La tradicionalidad discursiva como materia y las tradiciones discursivas como objeto de estudio*
}

\author{
Discursive traditionality as research matter and discourse traditions as object of \\ study
}

\author{
Araceli López Serena ${ }^{1}$ \\ 1 Universidad de Sevilla, España
}

Recibido: 20/05/2020; Aceptado: 16/07/2020

\section{Resumen}

Este trabajo plantea la diferencia que supone, en el modo en que se concibe la noción de tradición discursiva (TD), aproximarse a ella, bien con una perspectiva en la que las TD formen parte de la materia de estudio de una determinada investigación, bien con un enfoque que las erija en objeto de estudio. El artículo enmarca el surgimiento del concepto de TD en el interés actual por el estudio de la variación lingüística, atiende a su definición, en sentido amplio, desde el punto de vista de su consideración como materia de estudio, y se pregunta hasta qué punto es posible y/o necesario - $-\mathrm{y}$, en tal caso, desde qué punto de vistadiferenciar las TD en sentido estrecho, concebidas como objetos de estudio, de categorías como género, registro, estilo y perfil concepcional. A tenor de estas consideraciones, el uso "inflacionario" del término TD en los estudios de historia de la lengua española de la última década se explica en relación con su consideración preferente, en ellos, como materia y no como objeto de estudio.

Palabras clave: tradición discursiva; tradicionalidad discursiva; variación lingüística; objeto de estudio; materia de estudio; lingüística histórica.

\begin{abstract}
This paper focuses on the difference that exists between approaching the notion of discourse tradition (DT) either with a perspective in which DTs are part of the research matter, or with an approach that makes them the object of study. The article links the emergence of the concept of DT to the current interest in the study of linguistic variation, pays attention to its definition latu sensu, from the point of view of its consideration as research matter, and raises the question to what extent is it possible and/or necessary and, if so, from what point of view - to distinguish the DTs (stricto sensu, conceived as objects of study) from categories such as genre, register, style, and conceptional profile. In accordance with these considerations, the 'inflationary' use of the term DT in Spanish historical linguistics during the last decades is related to its preferential consideration as research matter and not as an object of study.
\end{abstract}

Keywords: discourse tradition; discursive traditionality; linguistic variation; object of study; research matter; historical linguistics. 


\section{INTRODUCCIÓN}

Es bien sabido que, como parte de su actual predilección por el estudio de la variación, la lingüística contemporánea ha ido prestando, en las últimas décadas, una atención creciente a los diversos moldes de construcción e interpretación de los discursos que constituyen los diferentes registros, estilos, tipos de textos o géneros, a los que en la Romanística germánica -y más concretamente en el marco de lo que podríamos llamar Lingüística de las variedades de filiación coseriana (en adelante $\mathrm{LVC})^{1}$ - se suele hacer referencia mediante el término tradiciones discursivas (en adelante TD). Esta consideración actual hacia la complejidad y la heterogeneidad reales del lenguaje (cf. Fernández Pérez 1999, cap. 1) no se ha visto necesariamente acompañada por una disociación clara entre los ámbitos de variación específicos que acotan estos y otros conceptos manejados en la bibliografía. Por un lado, hay autores que han llamado la atención sobre el problema de que, en relación con categorías como "tipo textual, género o clase textual, tradición textual y tradición discursiva", "nos encontramos ante conceptos borrosos y fronterizos" (Sáez Rivera 2007: 89). Por otro, como se ha puesto de manifiesto en diversas ocasiones (cf. López Serena 2007, 2011; Sáez Rivera 2007), en lo que atañe, por ejemplo, a los estudios de historia del español, el uso del concepto TD no es, en absoluto, uniforme. Esto no puede sorprender a nadie, sobre todo si se tiene en cuenta que tampoco de la lectura de los trabajos de los autores responsables de la acuñación, en el marco de la Romanística alemana, de esta noción como herramienta teóricometodológica (Koch 1987, 1997; Oesterreicher 1997; Jacob y Kabatek 2001; Kabatek 2005a, 2011[2018], 2015a, 2015b[2018], 2018; Wilhelm 2001, 2015; Lebsanft 2005, 2006) es posible extraer una única definición de consenso².

En relación con el debate de si sería conveniente o no especificar mejor la delimitación entre los conceptos mencionados, así como acerca de la oportunidad de promover una concepción unívoca de las TD, este trabajo se plantea la diferencia que supone, en el modo en que se interpreta la noción de TD, aproximarse a ella, bien con una perspectiva en la que las TD formen parte de la materia de estudio de una determinada investigación, bien con un enfoque que las erija en objeto de estudio ${ }^{3}$. La idea es que la consideración de esta sencilla distinción nos permitirá entender mejor a qué se debe la proliferación, en los estudios de historia de la lengua española, de usos extraordinariamente imprecisos del término TD -que algunos especialistas relacionaron, inicialmente, con una moda pasajera- o por qué su conversión prácticamente en un lugar común en el ámbito de la lingüística histórica — sobre todo hispánica e iberoamericana - no ha ido acompañada, en todos los casos, por un anhelo de rigor terminológico y exactitud conceptual en el empleo de este marbete.

En gran medida, el problema que se aborda en estas páginas fue anticipado ya, aunque en otros términos, primero por Kabatek (2015a) y luego por Octavio de Toledo (2018) ${ }^{4}$. Centrándonos en el primero de estos dos trabajos, que lamentablemente no se encuentra entre los que finalmente formaron parte del volumen sobre TD publicado en español por este autor en 2018, en él Kabatek insistía en la idea de que el alcance completo del concepto de TD le parecía aprehensible solo si efectuábamos un giro de perspectiva de 180 grados y procedíamos, no desde la categorización y la consiguiente adscripción de productos textuales a clases de TD preestablecidas —es decir, desde el punto de vista que yo denomino de objeto-, sino desde la descripción de todos los aspectos discursivo-tradicionales que fuéramos capaces de identificar en cada texto particular, o, lo que es lo mismo, a partir del enfoque que he considerado útil bautizar como de materia 5 . 
Por lo que respecta a los conceptos de objeto y materia de estudio a los que alude el título de este trabajo, y cuya importancia para los propósitos que persigue este artículo se acaba de poner de relieve, cabe señalar que con el término materia se hace referencia a la realidad fenoménica en toda su heterogeneidad y complejidad, en nuestro caso, a la complejidad y la heterogeneidad que imperan en todas las manifestaciones lingüísticas. A partir de esta realidad fenoménica -o materia de estudio-, los científicos, en nuestro caso los lingüistas, delimitamos y perfilamos objetos de estudio específicos en virtud de determinados criterios e intereses de investigación y sometiendo la materia de estudio a procesos de abstracción, modelización e interpretación a través de los cuales esta deja de ser realidad fenoménica y se torna constructo teórico (cf. López Serena 2006) ${ }^{6}$. Pues bien, en relación con el concepto de TD, la tesis principal de este artículo es que los dos grandes tipos de concepciones de esta noción que se documentan en la bibliografía - (i) su concepción amplia, de acuerdo con la cual todos los fenómenos variacionales (salvo quizás los netamente diatópicos y los diastráticos) son susceptibles de ser considerados TD, y (ii) su concepción estrecha, que clama por delimitar con precisión el ámbito de la TD frente al propio de los géneros, los tipos de textos, los registros, los estilos, etc. - derivan, no de desarrollos teóricos contrapuestos que se deban poner en una balanza a fin de dirimir cuál de las dos visiones es más o menos fiel a la acuñación originaria de este concepto o cuál resultaría preferible manejar en lo sucesivo, sino de la adopción, por parte de quienes prefieren una u otra concepción, de una perspectiva de materia o de una perspectiva de objeto de estudio; o, lo que es lo mismo, de la adopción de la noción de TD, ora para el ámbito de la lingüística histórica, cuyos fines están relacionados con la descripción lingüística, ora para el ámbito de la teoría lingüística y la lingüística general7.

El contenido del artículo se vertebra en torno a tres preguntas: (i) cómo se define, en sentido amplio, y desde el punto de vista de su consideración como materia de estudio, la noción de TD, (ii) hasta qué punto es posible (y/o necesario, deseable, etc.) —en este caso, en sentido estrecho y concebidas como objetos de estudio- diferenciar las TD de categorías como género, registro, estilo y perfil concepcional y (iii) en qué medida cabe retrotraer hasta su acuñación originaria por parte de Peter Koch tanto la concepción amplia como la concepción estrecha de las TD y, por ende, tanto la perspectiva descriptivista como la perspectiva teoricista que han convivido en su recepción. Todas y cada una de estas preguntas se abordarán desde un presupuesto de partida: la vinculación del concepto de TD con el actual interés de nuestra disciplina por el estudio de la variación lingüística (cf. López Serena, en prensa b). A este último respecto, en analogía con la oposición entre materia y objeto de estudio que servirá de hilo conductor a lo largo de todas las secciones que conforman este artículo, es necesario diferenciar también las nociones de variación y variedades. Precisamente, en el seno de la LVC en la que se enmarca este trabajo, se emplea conscientemente el término variedades y no variación ${ }^{8}$ para poner de relieve la necesidad de diferenciar entre, por una parte, la realidad de la variación en bruto, tal cual se puede observar en cualquier manifestación lingüística, independientemente del tipo de enfoque teórico que se adopte para su descripción, y, por otra parte, la abstracción, efectuada por el lingüista, a partir de esa realidad, de una serie de variedades que se instituyen como categorías de análisis y que están, por tanto, determinadas por una óptica teórica particular. Y, en el mismo sentido, Wulf Oesterreicher insiste, en varios de sus trabajos, en la distinción entre datos y hechos lingüísticos:

Una comprensión correcta de los textos y de los elementos que los integran es, por así decirlo, un requisito previo para lo que tenemos que hacer nosotros como lingüistas: es decir, transformar, en la perspectiva de opciones teóricas y metodológicas determinadas, estos DATOS en HECHOS lingüísticos. Y es evidente que este 
trabajo presupone una serie de abstracciones, distanciamientos, clasificaciones, categorizaciones e interpretaciones que se dan siempre a la luz de opciones teóricas determinadas que nos conducen al establecimiento y la descripción de hechos lingüísticos (Oesterreicher 2008: 240; la cursiva y la versalita son mías).

Por lo que respecta al concepto de TD y a su vinculación con el estudio de la variación, conviene poner de relieve dos aspectos esenciales de la LVC. Por un lado, el hecho de que este marco teórico asume que la variación es un rasgo inherente al lenguaje, corolario del universal genérico-esencial del lenguaje de la historicidad (cf. infra § 2, así como Oesterreicher 2001, 2006; López Serena 2013; Kabatek 2015a); de ahí que, en consonancia con ello, establezca un nivel específico para la consideración de las variedades lingüísticas (el nivel histórico) dentro de la segmentación analítica del lenguaje en diversos niveles de abstracción que caracteriza a esta escuela de pensamiento (cf. infra fig. 1). Por otro lado, la concepción, en línea con las propuestas de Coseriu, de la competencia lingüística como una técnica o un saber hacer al que es inherente el dominio de determinados moldes de variación, entre ellos las denominadas TD (cf. infra § 4). Ambas cuestiones atañen a la construcción teórica de la LVC y su planteamiento importa, fundamentalmente, a quienes adoptan una óptica de objeto de estudio. Sin embargo, la asunción de la variación como un rasgo inherente al lenguaje tiene también repercusiones en los enfoques descriptivos o de materia, puesto que obliga a considerar los datos a la luz de su estatus variacional. En el caso de las TD, como veremos en $\S 6$, esto llevará a los historiadores de la lengua que se hacen eco de esta noción a interpretar todos los datos lingüísticos teniendo siempre en consideración el contexto discursivo-tradicional en que tales datos aparezcan y a desconfiar, por ende, de toda lingüística de corpus que no tenga en cuenta la incidencia de la tradicionalidad discursiva en la configuración final de los testimonios (cf. infra $\S 3)^{9}$.

Más allá de esta introducción y de las conclusiones, para las que se reserva el último apartado, el artículo se divide en otros 5 epígrafes. En $\S 2$, se expone la importancia que, dentro de la LVC, tiene la asunción del universal genérico-esencial de la historicidad, atendiendo a la concepción de la competencia lingüística de los hablantes como un saber hacer. A continuación, en $\S 3$, se presentarán tanto la concepción amplia como la concepción estrecha de la noción de TD que desarrolló Peter Koch ${ }^{10}$. Comenzando por la concepción estrecha, en tercer lugar, en línea con lo sostenido por López Serena $(2011,2012)$, se abordará, desde el punto de vista de la teorización lingüística y, por tanto, con una óptica de objeto de estudio, la cuestión de la oportunidad de establecer una diferenciación, dentro del universo de lo discursivo-tradicional, entre géneros, registros, estilos y perfiles concepcionales. A este respecto, se prestará atención a las dimensiones universal e histórica del saber expresivo (§ 4) y se formulará (§ 5) la posibilidad de considerar, como ámbitos distintos, lo propio de la variación situacional y lo relativo a la variación textual o discursiva. Seguidamente, en $\S 6$, en relación con la concepción amplia de las TD, se pondrá de relieve en qué medida el uso "inflacionario" del término TD en los estudios de historia de la lengua española de la última década está relacionado con su consideración preferente como materia y no como objeto de estudio. 


\section{EL UNIVERSAL GENÉRICO-ESENCIAL DE LA HISTORICIDAD DEL LENGUAJE}

Por lo que respecta al interés por el estudio de la variación que caracteriza a la lingüística contemporánea, tal y como ya advirtió Coseriu (1957[19883]), buena parte de la lingüística del siglo XX - por ceñirnos a la historia más reciente de la disciplina- entendió que la existencia de variación y cambio lingüísticos —es decir, la ausencia de uniformidad y estabilidad- eran aspectos que precisaban una explicación. Según Coseriu, este "preguntarse por qué cambian las lenguas (como si no debieran cambiar), parece [apuntar a] una estaticidad natural perturbada, y hasta negada, por el devenir, que sería contrario a la esencia misma de la lengua" (Coseriu 1957[19883]: 11). Y, sin embargo, por una parte, es evidente que la lengua cambia, y, por otra, no cabe duda de que la realidad primaria del lenguaje $-\mathrm{y}$, por tanto, uno de sus rasgos inherentes (cf. infra) - es la variación.

En relación con ambas constataciones, Coseriu denuncia que "la perplejidad frente al cambio lingüístico y la tendencia a considerarlo como fenómeno espurio, provocado por 'factores externos', se deben al hecho de partir de la lengua abstracta $-y$, por lo tanto, estática-, separada del hablar y entendida como cosa hecha, como ergon, sin siquiera preguntarse qué son y cómo existen realmente las lenguas y qué significa propiamente un 'cambio' en una lengua” (Coseriu 1957[19883]: 30). Precisamente para evitar incurrir en este error, en el marco teórico coseriano la lengua no se concibe como un objeto ya dado, como un producto estático, reificado (como ع́pүov),

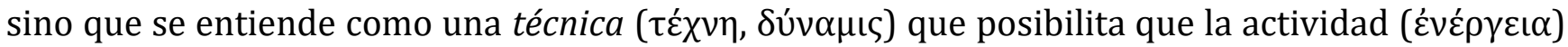
universal del hablar que llevan siempre a cabo individuos particulares se realice, por parte de estos, en cuanto miembros de comunidades históricas:

El lenguaje es una actividad humana universal que se realiza individualmente, pero siempre según técnicas históricamente determinadas [...]. En el lenguaje se pueden, por tanto, distinguir tres niveles: uno universal, otro histórico y otro individual (Coseriu 1957[1988³]: 269).

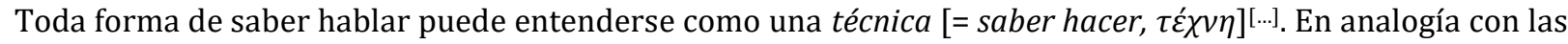
distinciones [entre diferentes niveles del lenguaje] cabe distinguir diversas técnicas del hablar: la técnica del hablar en general, la técnica de la lengua histórica y, finalmente, la técnica de los textos, esto es, el saber sobre cómo se configuran determinados textos o clases de textos (Coseriu 2007: 140):

Fig. 1. Los niveles universal, histórico y actual del lenguaje y los saberes elocucional, idiomático y expresivo de acuerdo con la propuesta de Coseriu (1956-1957) (cf. ahora Coseriu 2019: 32)

\begin{tabular}{|c|c|c|}
\hline $\begin{array}{c}\text { NIVEL } \\
\text { UNIVERSAL }\end{array}$ & $\begin{array}{c}\text { SABER } \\
\text { ELOCUCIONAL }\end{array}$ & $\begin{array}{l}\text { saber hablar en general, de acuerdo con los } \\
\text { principios generales del pensar y con la } \\
\text { experiencia general humana acerca del mundo }\end{array}$ \\
\hline $\begin{array}{c}\text { NIVEL } \\
\text { HISTÓRICO }\end{array}$ & $\begin{array}{c}\text { SABER } \\
\text { IDIOMÁTICO }\end{array}$ & $\begin{array}{l}\text { saber hablar de acuerdo con las normas de la } \\
\text { lengua que se realiza }\end{array}$ \\
\hline $\begin{array}{c}\text { NIVEL } \\
\text { INDIVIDUAL/ACTUAL }\end{array}$ & $\begin{array}{c}\text { SABER } \\
\text { EXPRESIVO }\end{array}$ & $\begin{array}{l}\text { saber hablar en situaciones determinadas, saber } \\
\text { estructurar los discursos de acuerdo con las } \\
\text { normas de cada uno de sus tipos }\end{array}$ \\
\hline
\end{tabular}


De estos tres niveles o perspectivas de análisis, que la figura 1 nos ayuda a visualizar mejor, el nivel histórico es, naturalmente, aquel en el que se ubican las lenguas y las modalidades de variación intralingüística que conforman el acervo idiomático, esto es, el saber hablar según la TRADICIÓN de una comunidad, que funciona como modelo para los actos lingüísticos particulares de los miembros de esa comunidad (Coseriu 1957[19883]: 45-46), así como, de acuerdo con la propuesta de Peter Koch (cf. infra § 3), las TD. Si proyectamos sobre esta figura la distinción entre materia y objeto de estudio que sirve de guía a este trabajo, el nivel actual del discurso correspondería a la materia de estudio, es decir, a la realidad de los testimonios discursivos y textuales que conforman una de las principales fuentes de datos para el estudio lingüístico, mientras que los niveles histórico y universal constituirían abstracciones propias del objeto de estudio (cf. también infra $\S 4)^{11}$.

En cuanto a su denominación, como ya se ha señalado, el término histórico, que da nombre al nivel en el que se ubican las lenguas y las modalidades de variación concebidas como normas históricas del hablar - y también, en la propuesta de Koch, las TD- está relacionado con el universal genérico-esencial de la historicidad del lenguaje (cf. Coseriu 1978). A este respecto, hablamos de un rasgo universal y esencial porque se trata de una propiedad del lenguaje que es racional o lógicamente necesaria para su constitución como tal, es decir, de una característica $a$ priori, y no estipulada secundariamente por inducción a partir de generalizaciones basadas en la observación de todas las lenguas. La historicidad es la característica determinante del lenguaje entendido como fenómeno social; de ahí que en el marco teórico coseriano no se suela hablar, como sí suele ser habitual en otras aproximaciones al estudio del lenguaje, de lenguas naturales, sino que se prefiera siempre la expresión lenguas históricas (cf. Oesterreicher 2006), y de ahí también que todos los componentes de la competencia lingüística que son generales, pero no universales, como las lenguas y los moldes textuales que utilizan los hablantes para construir sus discursos, se consideren (conjuntos de) normas históricas ${ }^{12}$.

Como se señalaba ya en López Serena $(2013, \S 1)$, el universal genérico-esencial de la historicidad no tiene solo que ver con el hecho de que las lenguas cambien necesariamente con el transcurso del tiempo —o de que estas deban cambiar para seguir funcionando-, algo en lo que se suele pensar inmediatamente cuando se asocia la palabra histórico a la historia de la lengua y, en consecuencia, a los conceptos de evolución o transformación. Hay, en realidad, tres razones por las que el lenguaje es un fenómeno histórico: (i) porque solamente existe en forma de lenguas históricas - y de tradiciones textuales - diferenciadas, sin intermediación de las cuales es imposible construir significados; (ii) porque tales lenguas y tales tradiciones textuales constituyen conjuntos de normas socialmente compartidas y son, por tanto, resultado de una tradición histórica, sujeta a continuos cambios, y (iii) porque el aprendizaje de estas lenguas y tradiciones textuales, entendidas como conjuntos de normas socialmente compartidas, es producto de un fenómeno de transmisión cultural.

Así las cosas, la historicidad tiene que ver, en primer lugar, más que directa y solamente con el cambio lingüístico, con la realidad, anterior al cambio, e intrínseca a toda forma del lenguaje, de la variación (cf. Oesterreicher 2006: 137-138). Al existir históricamente, el fenómeno del lenguaje cristaliza en numerosos tipos de variedades diferentes: en el ámbito estrictamente idiomático, en lenguas distintas, variedades diatópicas (dialectos) dentro de esas lenguas, variedades sociales (sociolectos) y variedades diafásicas (registros) que empleamos en las distintas situaciones de la vida; en el ámbito textual, en diversos tipos de textos, géneros o TD. De la ubicación de cada una de 
ellas en la teorización lingüística propia de la LVC, de su interrelación y de la delimitación entre unas categorías y otras nos ocuparemos en $\S \S 4$ y 5 . Antes de ello, dedicaremos un epígrafe exclusivo a la noción de TD.

\section{LA NOCIÓN DE TD EN EL SENO DE LA LINGÜÍSTICA DE LAS VARIEDADES DE FILIACIÓN COSERIANA}

Hace ya más de tres décadas, en su tesis de habilitación defendida en 1987, y a día de hoy desafortunadamente aún inédita, Peter Koch propuso convertir la tripartición coseriana del lenguaje que hemos visto reflejada supra en la figura 1 en cuatripartición, al subdividir el nivel histórico en dos dominios diferenciados que pusieran de relieve la falta de coincidencia entre (i) el saber histórico que tiene que ver con la competencia idiomática y (ii) el producir textos según tradiciones y modelos históricos, que pertenece también al saber sociohistóricamente determinado, pero que es independiente de las tradiciones de las lenguas particulares. La idea aparecía ya prefigurada en la intervención de Coseriu que se registra en B. Schlieben-Lange y H. Weydt (1979: 77), aunque a tenor de lo que en ella se expresa no es posible decantarse ni por la ubicación de las TD en el nivel histórico ni por su localización en el nivel individual del lenguaje:

wir müssten zu sicheren Kriterien gelangen, die uns erlauben, stets zwischen Einzelsprache und einzelsprachlichen Texten, dir für die Sprachgemeinschaft charakteristisch sein können, zu unterscheiden. Dies betrifft übrigens nicht nur die Texte, die in ihrem Wortlaut traditionell sind (wie Guten Morgen gegenüber *bon matin, *buon mattino), sondern auch die traditionellen, eventuell ebenfalls nur in einer Sprachgemeinschaft existierenden Textformen. Schon vor vielen Jahren habe ich darauf hingewiesen, daß es Sonette $\mathrm{zu}$ einer bestimmten Zeit nur in der italienischen Sprachgemeinschaft gab. Aber ein Sonett war trotzdem keine Form des Italienischen (der italienischen Sprache), sondern nur eine Art Text in der italienischen Sprachgemeinschaft [...]. Ebenso ist das „Haiku” eine für Japan charakteristische literarische Gattung. Dies bedeutet aber nicht, daß es eine Form des Japanischen als Sprache ist: es ist nur eine Art Text, die gerade in der japanischen Sprachgemeinschaft existiert.

[debemos conseguir criterios firmes que nos permitan diferenciar sistemáticamente entre una lengua histórica (Einzelsprache) y los textos redactados en una determinada lengua histórica (einzelsprachlichen Texten) que puedan ser característicos de la comunidad lingüística. Esto atañe no solamente a los textos, que son textualmente tradicionales (como good morning frente a *bon matin, *buon mattino), sino también a las formas textuales asimismo tradicionales y que eventualmente existan solo en una determinada comunidad lingüística. Hace ya muchos años llamé la atención sobre el hecho de que hasta un determinado momento solo hubo sonetos en la comunidad lingüística italiana. Pero un soneto no era, sin embargo, una forma del italiano (de la lengua italiana), sino más bien una clase de texto emergida en la comunidad lingüística italiana [...]. Del mismo modo el haiku es un género literario característico de Japón. Pero esto no significa que sea una forma de la lengua japonesa. Se trata de una clase de texto que existe en la comunidad lingüística japonesa (la traducción es mía)]

Si incluimos esta nueva diferenciación entre lenguas históricas y formas textuales históricas (o, en términos de P. Koch, TD) en el esquema que ofrecía la figura 1, siguiendo, para ello, la propuesta del propio Koch, el resultado sería el siguiente: 
Fig. 2. Niveles y dominios de lo lingüístico (apud Koch 1997: 45; cf. también Koch 2008: 54)

\begin{tabular}{|l|l|l|}
\hline \multicolumn{1}{|c|}{ NIVEL } & \multicolumn{1}{|c|}{ DOMINIO } & \multicolumn{1}{c|}{ TIPO DE REGLAS } \\
\hline universal & actividad del hablar & reglas elocucionales \\
\hline \multirow{2}{*}{ histórico } & lengua histórica particular & reglas idiomáticas \\
\cline { 2 - 3 } & tradición discursiva & reglas discursivas \\
\hline actual/individual & discurso & \\
\cline { 1 - 3 } & &
\end{tabular}

De acuerdo con esta primero tri- y luego cuatripartición, el saber elocutivo es por definición común para hablantes de lenguas distintas como el español, el francés, el italiano o el alemán, pero el saber idiomático es específico de cada lengua, por lo que, aunque como aprendices de lenguas extranjeras podamos hacer uso siempre del mismo saber elocutivo a la hora de construir discursos congruentes, para cada nueva lengua que deseemos estudiar resulta imprescindible adquirir un saber o acervo idiomático nuevo: no en vano "es posible saber una lengua y poseer un saber elocucional deficiente, así como es corriente que se posea un amplio saber elocucional y se hable mal una lengua determinada" (Coseriu 1956-1957: 24; cf. ahora Coseriu 2019: 33-34).

Del mismo modo, también el dominio de modelos textuales históricamente determinados es específico para determinadas comunidades sociohistóricas, aunque, tal como puso de relieve el propio Koch, su extensión no coincida ni necesaria ni habitualmente con la de las comunidades idiomáticas. Y es que, aunque cuando en el marco teórico coseriano inicialmente se hablaba de normas históricas tradicionales generalmente se entendía que estas eran las que conformaban las distintas lenguas particulares (razón por la que para el dominio de las técnicas históricas del hablar se suele emplear el término saber idiomático), la reformulación hecha por Koch destaca que "los textos tienen también sus tradiciones particulares, independientes de las lenguas" (Coseriu 2007: 137-138). Este es el motivo de que podamos hablar, asimismo, dentro de las tradiciones del hablar (Traditionen des Sprechens, cf. Schlieben-Lange 1983), de tradiciones textuales, o —como se suele preferir en la actualidad- de $T D$, tanto en relación con "los textos incorporados a la tradición lingüística misma” (Coseriu 2007: 138) (por ejemplo, las formas históricamente establecidas en una comunidad idiomática para el saludo o para las secuencias de cierre de una conversación) ${ }^{13}$, como en "el caso de los [tipos de] textos supraidiomáticos, [...], [en relación con los cuales] debería resultar evidente que existe una configuración tradicional enteramente independiente de la tradición del hablar según una técnica transmitida históricamente (=independiente de las lenguas históricas)" (Coseriu 2007: 13914).

Así las cosas, podemos convenir que, en el marco de la LVC, la noción de TD se refiere a todas las formas de construcción del discurso de carácter histórico que no sean de naturaleza idiomática. Desde el punto de vista de su intensión, el concepto de TD está vinculado con la variación lingüística de naturaleza textual o discursiva. En este sentido, la definición que ha encontrado mayor número de adeptos es la propuesta por Kabatek (2005a: 159), de acuerdo con la cual una TD consiste en "la repetición de un texto o de una forma textual o de una manera particular de escribir o de hablar que adquiere valor de signo propio" (cf. ahora también Kabatek 2018, cap. 8). Desde el punto de vista de su extensión, para Koch, las reglas discursivas, que proporcionan a los hablantes modelos 
para realizar de manera adecuada sus discursos, "remiten a tradiciones discursivas, es decir, a determinados estilos, géneros, clases de textos, universos discursivos, actos de habla, etc., todos los cuales aprehenden clases de discursos" (Koch 1987: 31; la traducción es mía)15.

Como vemos, la laxitud de la definición intensiva y extensiva del término TD ha conducido, de una parte, a su solapamiento con categorías tradicionalmente aplicadas a la descripción de la variación lingüística como registro o estilo, que, por un lado, como acabamos de comprobar, Koch también considera TD, y que, por otro lado, caben perfectamente dentro de la definición de Kabatek a la que se acaba de hacer referencia, en la medida en que tanto los registros como los estilos se pueden interpretar como "maneras particulares de escribir o de hablar que adquieren valor de signo propio"; de hecho, incluso los fenómenos de variación diatópica y diastrática encontrarían acomodo dentro de esta definición tan amplia, puesto que son tan particulares como los registros y los estilos y poseen el mismo valor de signo propio que aquellos ${ }^{16}$. De otra parte, la etiqueta $T D$ confluye también con la noción, asimismo tradicional, de género (cf. Kabatek 2011[2018]), así como con conceptos procedentes de propuestas de teorización lingüística más recientes, como los de clases de textos, universos discursivos o actos de habla. A este respecto, caben, al menos, dos posicionamientos que tienen que ver con dos posibles enfoques o finalidades de estudio. Por un lado, hay que considerar el punto de vista que da preferencia a la materia de estudio (cf. supra $\S 2$ e infra § 6). Este punto de vista es el que impera en la descripción lingüística que se practica, por ejemplo, en el campo de la historia de la lengua, entre quienes coinciden en rechazar la conversión de la lingüística histórica en una lingüística de corpus que no tenga en cuenta los factores discursivo-tradicionales que condicionan la interpretación de cualquier dato lingüístico. Este rechazo es una constante entre los estudiosos de las $\mathrm{TD}$, como se deriva de las declaraciones, en este sentido, de Kabatek (2008: 8) y Koch (2008: 80), que se reproducen a continuación:

[S]e trata de modificar [...] un monolitismo que parte del supuesto de la existencia de una $-\mathrm{y}$ una solagramática representativa de cada lengua y cada época, monolitismo reanimado por modelos actuales y por una lingüística de corpus en la que se supone que la variación textual no es más que un problema de cantidad y que, a partir de un cierto tamaño de la muestra, la variación se esfuma en la nada del "ruido" estadísticamente irrelevante (Kabatek 2008: 8).

El estudio diacrónico de una lengua particular que se basa empíricamente en textos ('discursos') no tiene que engañarse con la ilusión de que los datos extraídos de estos discursos reflejen directamente reglas idiomáticas de la lengua en cuestión ni que los datos sacados de discursos sucesivos en el tiempo reflejen directamente cambio de reglas idiomáticas. Hay que tener en cuenta los "filtros" no solo de las variedades lingüísticas, sino también de las tradiciones discursivas que intervienen en cada discurso individual. Esta consideración conlleva consecuencias importantísimas para la metodología de una lingüística del corpus (cfr. Oesterreicher 2001: 1569s.; Kabatek 2005a: 163s., 172-174) (Koch 2008: 80; cursiva original).

En consonancia con ambos, también Oesterreicher se siente en la necesidad de puntualizar que "los textos y discursos concretos que forman el corpus de la investigación [en lingüística histórica] no se prestan [jamás] a un simple cálculo estadístico", por lo que "ni siquiera la multiplicación de la variedad de los géneros textuales protege al investigador en un estudio estadístico del peligro de perder información valiosa para la caracterización de variedades y tradiciones discursivas" (Oesterreicher 2008: 241).

Desde esta perspectiva de materia, es perfectamente posible operar con una concepción ancha de las TD como la que lleva a Koch a considerar como tales los estilos, los géneros, las clases de 
textos, los universos discursivos, los actos de habla, etc., y a Kabatek a definirlas en términos de repeticiones de textos, formas textuales o maneras particulares de escribir o de hablar que adquieren valor de signo propio. Y es que, como señala a este respecto Álvaro Octavio de Toledo,

[u]na definición basada en la idea de repetición evocadora y ampliable a elementos o secuencias inferiores al texto e incluso a la oración convierte a las TD, como es fácil de entender, en entidades extraordinariamente atractivas para quien investiga la historia de la lengua, por cuanto le proporcionan una herramienta previamente inexistente para conectar directamente la repetición de un elemento o construcción (su frecuencia, en suma) con una distribución restringida (o, al menos, dominante) en un conjunto de textos interrelacionables según criterios varios (pero no necesariamente dependientes unos de otros, ni en términos genéricos ni de rasgos de género: una constelación textual) (Octavio de Toledo 2018: 119; cursiva original) ${ }^{17}$.

Por otro lado, si se adopta un enfoque de objeto de estudio - y no de materia-, es decir, si el cariz de la investigación es de índole teórica y no meramente descriptiva, a buen seguro surgirá la necesidad de apostar por una delimitación lo más precisa posible de las diferentes categorías conceptuales implicadas en la aprehensión de la variación textual y discursiva (cf. infra §§ 4 y 5). De hecho, en opinión de Octavio de Toledo, la desazón por la falta de precisión en la delimitación del concepto de TD puede llegar a afectar también a los propios historiadores de la lengua y, por tanto, a quienes adoptan una perspectiva de materia de estudio:

[L]a amplitud misma de la definición también puede producir, quizá, cierto desasosiego en el investigador dedicado a la sintaxis histórica: lo característico de las construcciones y los elementos gramaticales es, precisamente, su carácter repetitivo, su tendencia a la fijación y, en términos históricos, su emergencia y asentamiento a través de una creciente rutinización (en el sentido de Haiman 1994); siendo esto así, ¿dónde cabe situar el límite entre la repetición rutinaria, automatizada y semiconsciente de las estructuras sintácticas y la repetición evocadora, consciente, quizá incluso "psicológicamente relevante" [...] [en el sentido Boyer (1990)] de las TD? (Octavio de Toledo 2018: 119-120) ${ }^{18}$.

En la obra que se suele considerar fundacional en relación con la investigación sobre TD, que es la ya mencionada tesis de habilitación de Peter Koch (1987), conviven las dos perspectivas que en este trabajo hemos denominado de materia y de objeto de estudio. Por una parte, Koch se proponía principalmente dos objetivos netamente descriptivos, relacionados, por tanto, con el enfoque de materia: "por un lado, el análisis lingüístico del género dictamen a partir de textos prototípicos, redactados en latín y por primera vez en volgare; por otro lado, el análisis lingüístico del primer empleo del volgare en el género dictamen" (Koch 1987: 3; la traducción es mía) ${ }^{19}$. Por otra parte, Koch, desde una aproximación de objeto de estudio, también considera que gracias a su aportación disponemos "de un marco teórico lingüístico categorial, dentro del cual se pueden situar, delimitar e interrelacionar con exactitud las diferentes preguntas de investigación que surjan en el abordaje de los dictamina" (Koch 1987: 36; la traducción y la cursiva no preceptiva son mías) ${ }^{20}$.

La convivencia de estos dos puntos de vista, no siempre fáciles de compatibilizar entre sí, en todos los acercamientos posteriores a la noción de TD no ha hecho más que acrecentar la sensación de confusión y la percepción de que quienes emplean el concepto de TD como herramienta para el análisis filológico y el estudio de fenómenos de variación y cambio lingüísticos determinados y quienes buscan fijar su definición como categoría teórica no terminan de ponerse de acuerdo en cómo perfilar de manera uniforme y unívoca esta noción; de ahí que tener en cuenta la línea que separa los acercamientos que hemos denominado de materia de aquellos que hemos considerado de objeto de estudio nos parezca crucial para explicar los motivos por los que la concepción amplia 
y la concepción estrecha de las TD se gestaron simultáneamente en la obra fundacional de Koch y han continuado conviviendo en la bibliografía hasta el presente. Ahora bien, aunque en las aproximaciones de materia o descriptivas puede ser innecesario - e incluso contraproducenteadoptar un concepto estrecho de $\mathrm{TD}^{21}$, en el ámbito de la teorización lingüística de filiación coseriana algunos autores han apostado por revisar la pertinencia de ubicar, tal y como se ha visto que ocurre en la figura 1 supra, el saber expresivo única y exclusivamente en el nivel actual del discurso (§ 4) y han explorado la oportunidad de establecer una diferenciación explícita entre el ámbito de la variación situacional y el ámbito de la variación discursiva (§ 5). Retomando los términos de la definición de Kabatek, ello implicaría contemplar separadamente, por un lado, la repetición de textos o de formas textuales, que pertenecería a la variación discursiva y dispondría de sus propios objetos de estudio - los modos de estructurar ciertos tipos de discursos (cf. infra $\S \S 4$ y 5)-, y, por otro, la repetición de maneras particulares de escribir o de hablar, que quedaría vinculada al estudio de la variación situacional, y cuyos objetos de estudio serían los modos de hablar en tipos de circunstancias (cf., de nuevo, infra §§ 4 y 5). En las dos siguientes secciones de este trabajo, se pasará revista, de manera muy somera, a esta propuesta, cuyo desarrollo más pormenorizado se puede consultar en otros trabajos (cf. López Serena 2011, 2012), y que se trae a colación en este contexto simplemente para ilustrar el contraste entre el enfoque de objeto de estudio desde el que tal propuesta se formuló, enfoque que prevalecerá en §§ 4 y 5, y la óptica que atiende a las TD como parte de la materia de estudio, que se analizará en $\S 6$.

\section{EL SABER EXPRESIVO COMO OBJETO DE ESTUDIO}

Como hemos visto en $\S 2$, junto con los saberes elocucional e idiomático, vinculados, respectivamente, con los niveles universal e histórico del análisis lingüístico, Coseriu distinguió también un tercer componente de la competencia lingüística, el saber expresivo, relacionado con el nivel individual del lenguaje. Bajo este marbete queda subsumida la competencia para construir y entender actos de habla determinados, de acuerdo con las circunstancias concretas de la comunicación, esto es, el saber necesario para construir e interpretar el sentido discursivo, que otros autores prefieren denominar saber textual, saber discursivo, competencia comunicativa o competencia pragmática.

Pese a su vinculación con el nivel individual, sobre el que se proyecta, el saber expresivo (que también es perfectamente posible denominar textual, discursivo, o pragmático) necesariamente ha de hundir sus raíces en los niveles histórico y universal del análisis, por cuanto

\footnotetext{
si bien es cierto que el escalón del lenguaje al que corresponde el saber expresivo es "particular", en el sentido de que se trata de realizaciones concretas, individuales y ocasionales de la actividad lingüística, ello no implica que ese saber sea particular en cuanto a su contenido y a su esfera de aplicación, ni que sea necesariamente individual en cuanto a su extensión en las comunidades lingüísticas. Por su contenido, el saber expresivo se aplica a tipos de circunstancias y, por ende, de discursos [...]. Y en cuanto a su extensión, este saber puede, por ciertos aspectos, pertenecer a comunidades muy limitadas, y hasta a un solo individuo, pero presenta también aspectos de extensión mucho más amplia. [...] De todos modos, salvo casos especiales, LOS ASPECTOS INTERESANTES DEL SABER EXPRESIVO SON LOS QUE PRESENTAN en ambos sentidOS, CIERTO GRADO DE GENERALIDAD. TALES ASPECTOS PUEDEN SER UNIVERSALES O HISTÓRICOS (Coseriu 1956-1957, apud Coseriu 2007: 142-143, n. 124; cursiva original, la versalita es mía).
} 
Debido a esto, en relación con el saber expresivo nos enfrentamos al mismo dilema que en el ámbito de la pragmática suscitó la discusión sobre si se trataba de un nuevo nivel de análisis lingüístico o más bien de una perspectiva que habría de englobar la consideración de todo el resto de niveles. Por ello, si por una parte podemos concebirlo como ámbito de saber autónomo con respecto al saber hablar en general y al saber idiomático, por otra parte es obvio que si lo identificamos con el saber necesario para la construcción e interpretación de sentido, el saber expresivo tendría que comprender, dentro de sí, los saberes tanto elocutivo como idiomático, así como el saber histórico que no es puramente idiomático, sino que se corresponde con el dominio de los modelos textuales o TD sociohistóricamente determinados; de ahí que Koch entienda, en el esquema que hemos reproducido en la figura 2, el discurso únicamente como nivel de realización de los distintos saberes del hablante —es decir, como materia-, y que consigne el saber relacionado con la producción del discurso en el nivel histórico:

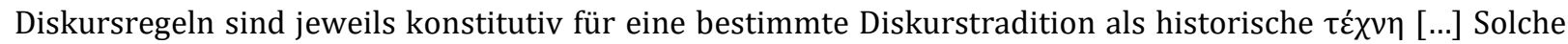
Diskurstraditionen sind freilich $\tau \varepsilon ́ \chi v \alpha \iota$ anderer Art als die Einzelsprachen; sie sind nicht einzelsprachlich und nicht einmal in erster Linie überhaupt sprachlich begründet. Sie stehen vielmehr in enger Verflechtung mit gesellschaftlichen, wirtschaftlichen, rechtlichen, religiösen, literarischen und anderen Traditionen (Koch 1987: 32).

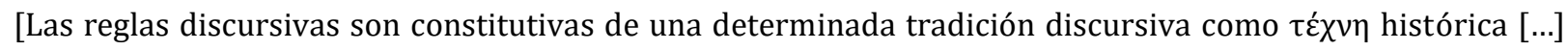

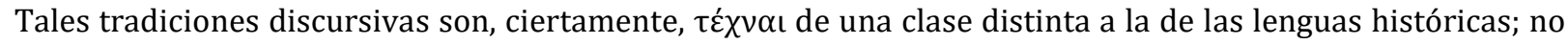
son idiomáticas y ni siquiera tienen una base en primera instancia lingüística. Más bien se hallan estrechamente entrelazadas con tradiciones sociales, económicas, jurídicas, religiosas, literarias y de otro tipo (la traducción es mía)].

Para Koch (1987: 31), “[p]or lo que concierne [...] al saber expresivo, este no es ni actual ni tampoco individual. [...] En la medida en que se trata de un saber profundamente impregnado de historicidad, el saber expresivo pertenece al mismo nivel que el saber idiomático" (mi traducción) 22. A ello añade en nota a pie de página: "El saber expresivo no pertenece, por tanto, al nivel del discurso, sino al nivel histórico, dentro del ámbito de las tradiciones discursivas, que, eso sí, están más arraigadas en el nivel del discurso que las lenguas históricas" (Koch 1987: 32, n. 24; la traducción es mía) ${ }^{23}$.

Así las cosas, en su opinión, en la medida en que el dominio de lo discursivo se concibe no como producto ( $\varepsilon \rho \gamma o v)-y$, por tanto, en relación con la oposición entre materia y objeto de estudio que vertebra estas páginas, como materia de la que extraer datos para la descripción lingüística一, sino

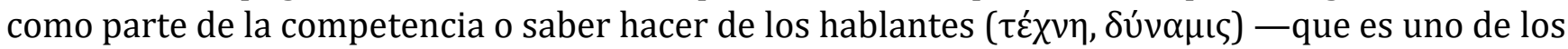
objetos de estudio posibles en la teorización lingüística que propone modelos de tal competencia, ya no es posible ubicarlo únicamente en el nivel individual o actual del lenguaje: "Atribuir al discurso como nivel genuinamente actual del lenguaje una $\delta$ v́$\alpha \mu \iota \varsigma$, es decir, un saber reglas, sería una contradicción en sí misma, puesto que las reglas entrañan tipificaciones y no pueden ser empleadas una única vez" (Koch 1987: 31; la traducción es mía) ${ }^{24}$. A la hora de argumentar de este modo, Koch apela a Wittgenstein — "De acuerdo con Wittgenstein, 'es imposible que una sola persona haya seguido una regla solo una vez’ (1967, § 199)” (Koch 1987: 31, n. 21; la traducción es mía $)^{25}$ - y parece entender, por tanto, que la competencia lingüística de los hablantes sería, por antonomasia, una competencia o un saber expresivo, dentro del cual se podrían distinguir saberes universales y saberes históricos (idiomáticos y discursivos), todos ellos necesarios para la 
producción lingüística individual en el marco de una constelación comunicativa determinada. Para reflejar gráficamente este hecho, Schlieben-Lange reformuló las correspondencias lenguaje-nivel universal, lengua-nivel histórico y texto-nivel individual establecidas por Coseriu de acuerdo con el siguiente esquema:

Fig. 3. Lo universal, lo histórico y lo individual como dimensiones del saber expresivo (apud Schilieben-Lange 1990: 115$)^{26}$

\begin{tabular}{|c|c|c|}
\hline lenguaje (Sprechen) & lengua (Einzelsprache) & habla/discurso (Text) \\
\hline universal & universal & universal \\
\hline & histórico & histórico \\
\hline & & individual \\
\hline
\end{tabular}

En el mismo sentido, Peter Koch afirma lo siguiente:

Das expressive Wissen ist nur sprachbezogenen Wissen, ebenso wie übrigens auch das elokutionelle Wissen, das mit interaktionellen, psysichen, ontogenetischen, physiologischen, logischen und anderen Faktoren eine unauflösbare Einheit bildet [...]. Das einzelsprachliche Wissen ist demgegenüber nicht nur sprachbezogen, sondern genuin sprachlich [...]. Der aktuelle Diskurs als konkreteste Stufe des Sprachlichen muss dann schliesslich interaktionellen, psychischen usw. (Sprechtätigkeit), rein sprachlichen (Einzelsprache), gesellschaftlichen, kulturellen usw. (Diskurstradition), und schliesslich auch situativen und ganz individuellen Belangen genüngen, ist also ebenfalls nur sprachbezogen zu nennen (Koch 1987: 32).

[El saber expresivo solo puede ser un saber relativo a una lengua, al igual que el saber elocucional que conforma una unidad indisoluble con factores psíquicos, ontogenéticos, fisiológicos, lógicos y de otro tipo [...] Frente a ellos, el saber idiomático no es meramente relativo a una lengua, sino genuinamente lingüístico [...] Asimismo el discurso actual, como nivel más concreto de lo lingüístico, y que debe satisfacer, por tanto, requisitos interaccionales, psíquicos, etc. (de la actividad universal del hablar), exclusivamente idiomáticos (de la lengua histórica), sociales, culturales, etc. (relativos a la tradición discursiva) y, finalmente, también de carácter situacional y completamente particular, solo se puede aprehender en relación con una lengua (la versión, que no es traducción literal en todos sus puntos, es mía)].

A tenor de todo lo dicho, Koch propone los siguientes esquemas, en algunas de cuyas celdas he conservado los términos alemanes originarios: 
Fig. 4. La naturaleza lingüística, idiomática, actual, individual y técnica del lenguaje, la lengua, la tradición discursiva, el acervo idiomático individual y el discurso (apud Koch 1987: 33)

\begin{tabular}{|c|c|c|c|c|c|c|}
\hline & Relacionado con & Idiomático & Actual & Individual & \multicolumn{2}{|c|}{ 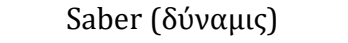 } \\
\hline & & & & & $\begin{array}{c}\text { Histórico } \\
\text { (historisch) }\end{array}$ & $\begin{array}{l}\text { Sujeto a } \\
\text { reglas } \\
\text { (regelhaft) }\end{array}$ \\
\hline $\begin{array}{l}\text { Lenguaje } \\
\text { (Sprechtätigkeit) }\end{array}$ & + & - & - & - & - & + \\
\hline $\begin{array}{l}\text { Lengua } \\
\text { (Einzelsprache) }\end{array}$ & & + & - & - & + & + \\
\hline $\begin{array}{l}\text { Tradición discursiva } \\
\text { (Diskurstradition) }\end{array}$ & + & - & - & - & + & + \\
\hline $\begin{array}{l}\text { Acervo idiomático } \\
\text { individual } \\
\text { (Individualsprache) }\end{array}$ & + & - & - & + & + & + \\
\hline Discurso (Diskurs) & + & - & + & + & - & - \\
\hline
\end{tabular}

Fig. 5. El lenguaje, las lenguas, las tradiciones discursivas, los acervos idiomáticos individuales y los discursos y sus correspondencias con los niveles universal, histórico y actual del lenguaje (apud Koch 1987: 35)

\begin{tabular}{|c|c|c|c|c|}
\hline & & 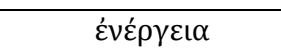 & $\delta u ́ v \alpha \mu t \varsigma$ & 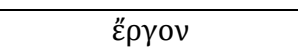 \\
\hline Nivel universal & $\begin{array}{l}\text { Lenguaje } \\
\text { (Sprechtätigkeit) }\end{array}$ & Hablar en general & $\begin{array}{l}\text { Saber elocutivo } \\
\text { (reglas del lenguaje) }\end{array}$ & $\varnothing$ \\
\hline \multirow[b]{3}{*}{$\begin{array}{l}\text { Nivel } \\
\text { histórico }\end{array}$} & lengua & $\begin{array}{l}\text { Práctica de una } \\
\text { lengua histórica }\end{array}$ & $\begin{array}{l}\text { Saber idiomático } \\
\text { (reglas idiomáticas) }\end{array}$ & $\begin{array}{l}\text { (gramática, } \\
\text { diccionarios, etc.) }\end{array}$ \\
\hline & Tradición discursiva & $\begin{array}{l}\text { Práctica de una } \\
\text { tradición discursiva }\end{array}$ & $\begin{array}{l}\text { Saber expresivo } \\
\text { (reglas discursivas) }\end{array}$ & $\begin{array}{l}\text { (retórica, poética, } \\
\text { estilística, etc.) }\end{array}$ \\
\hline & $\begin{array}{l}\text { Acervo idiomático } \\
\text { individual }\end{array}$ & $\begin{array}{l}\text { Práctica lingüística } \\
\text { individual }\end{array}$ & $\begin{array}{l}\text { Acervo idiomático } \\
\text { individual } \\
\text { (idiomático, } \\
\text { expresivo, idiolectal) }\end{array}$ & $\begin{array}{l}\text { (análisis estilístico de } \\
\text { autores específicos, } \\
\text { etc.) }\end{array}$ \\
\hline Nivel actual & discurso & habla & $\varnothing$ & "texto" \\
\hline
\end{tabular}


Como se ha adelantado ya, la razón principal por la que la tripartición coseriana se decantaba por una consideración autónoma de los tres tipos de saberes mencionados (elocutivo, idiomático y expresivo) estribaba en el interés de Coseriu por mostrar cómo estos saberes constituían conjuntos autónomos de competencias, en la medida en que "alguien puede saber hablar en general y saber español pero ser incapaz de hablar de manera apropiada a un niño, de pronunciar un discurso político o de escribir una carta de pésames, precisamente por carecer, en cada caso, del correspondiente saber expresivo" (Coseriu 1956-1957: 19) ${ }^{27}$. Ello no obsta, sin embargo, para reconocer, al mismo tiempo, que el saber expresivo posee sus propias universalidad e historicidad; de ahí que sea necesario recurrir a parámetros tanto históricos como universales en la delimitación tanto de registros como de géneros y de lo que en la lingüística de las variedades de filiación coseriana se denominan perfiles concepcionales y tradiciones discursivas (cf. infra $\S 5$ ).

Son universales los que se relacionan con la naturaleza propia del hombre y con la experiencia humana en general; son históricos los que dependen de ámbitos de experiencia o de cultura históricamente determinados. Es decir que el saber expresivo posee su propia universalidad y su propia historicidad. Existen, en efecto, modos universales (no idiomáticos) de hablar en tipos de circunstancias y modos universales de estructurar ciertos tipos de discurso (por ejemplo, discursos narrativos), y, análogamente, modos históricos de ambas especies. [...] Los aspectos históricos del saber expresivo pueden superar en extensión las comunidades idiomáticas abarcando varias de ellas (ser, por ejemplo, propios de la 'cultura occidental'), superar los límites de las comunidades idiomáticas sin abarcarlas (ser, por ejemplo, propios de los estratos cultos de las comunidades 'occidentales'), corresponder a comunidades menores dentro de las comunidades idiomáticas; y pueden hasta coincidir con las comunidades idiomáticas, en la medida en que los límites de ciertos hechos de experiencia o de cultura coincidan, precisamente, con los límites de esas comunidades (Coseriu 1956-1957, apud Coseriu 2007: 142-143, n. 124).

\section{LA INTERRELACIÓN ENTRE VARIACIÓN SITUACIONAL Y VARIACIÓN DISCURSIVA EN EL CONCEPTO DE TD}

Como hemos podido leer en $\S 4$, para Koch el saber expresivo "no es ni actual ni tampoco individual" (Koch 1987: 31; la traducción es mía). En su opinión, este dominio de la competencia lingüística "no pertenece, por tanto, al nivel del discurso, sino al nivel histórico" (Koch 1987: 32, n. 24; la traducción es mía). En realidad, Coseriu había ido más allá del nivel histórico cuando indicó que, "[p]or su contenido, el saber expresivo se aplica a tipos de circunstancias y, por ende, de discursos" (Coseriu 1956-1957, apud Coseriu 2007: 143, n. 124), así como cuando, en ese mismo fragmento, abogaba por destacar como "aspectos interesantes del saber expresivo" "los que presentan [...] cierto grado de generalidad" y señalaba cómo “[t]ales aspectos [podían] ser universales o históricos" (hecho que reflejaría también Schlieben-Lange al diseñar la figura 3 que se ha reproducido en $\S 4$ supra). En la continuación de este pasaje, tal y como hemos visto en la última cita sangrada reproducida al final de $\S 4$, Coseriu afirmaba lo siguiente: "Existen, en efecto, modos universales (no idiomáticos) de hablar en tipos de circunstancias y modos universales de estructurar ciertos tipos de discurso (por ejemplo, discursos narrativos), y, análogamente, modos históricos de ambas especies" (Coseriu 1956-1957, apud Coseriu 2007: 142-143, n. 124).

Sin embargo, como se ha podido anticipar ya en $\S 3$, lo habitual es que en el ámbito de la LVC en general, y en el del abordaje de la cuestión de las TD en particular, esta última diferenciación entre saber hablar en tipos de circunstancias y saber estructurar ciertos tipos de discursos- haya 
brillado por su ausencia. No en vano, siguiendo más bien la indicación coseriana de que existe una conexión entre la variación situacional y la variación discursiva, en la medida en que, como acabamos de volver a recordar, de acuerdo con Coseriu, "[p] or su contenido, el saber expresivo se aplica a tipos de circunstancias y, POR ENDE, de discursos" (la versalita es mía), desde la misma acuñación del concepto de TD, Peter Koch estableció una vinculación entre las TD y ciertos modos específicos de la variación situacional concebida como un continuum entre los polos de la máxima inmediatez y la máxima distancia comunicativa:

Intensional betrachtet [...], legt sich auf der historischen Ebene also sowohl der Bereich der Einzelsprache (Sprachregeln) als auch der Bereich der Diskurstraditionen (Diskursregeln) um den Kern der Sprechtätigkeit (Sprechregeln) herum, jedoch jeweils in anderer Richtung. Die Diskursregeln haben dabei insofern einen mehr äusserliche Status [...], als sie stets zu den Sprachregeln hinzutreten und im Gegensatz zu diesen bereits auf Typen von Situationen bezogen sind (Koch 1987: 33; la cursiva es mía).

[Considerado desde el punto de vista intensional [...], en el nivel histórico se ubican tanto el dominio de la lengua histórica (reglas lingüísticas) como el dominio de las tradiciones discursivas (reglas discursivas), ambos en torno al núcleo de la actividad del hablar (reglas del lenguaje), aunque cada uno en un sentido distinto. Las reglas discursivas manifiestan un estatus más externo [...], por cuanto tienen acceso a las reglas idiomáticas, pero, al contrario que estas, están ya vinculadas de antemano a tipos de situaciones (la traducción es mía)].

Como pone de manifiesto la figura 6, las nociones de inmediatez y distancia comunicativa ${ }^{28}$, acuñadas por Koch y Oesterreicher (1985) y dadas a conocer internacionalmente sobre todo a partir de Koch y Oesterreicher (1990[2007]), buscan aprehender la idea de que diferentes constelaciones situacionales propician estrategias de verbalización también distintas:

Fig. 6. Parámetros situacionales de la inmediatez y la distancia comunicativa y estrategias de verbalización correspondientes (Koch y Oesterreicher [1990]2007: 34)

Inmediatez

\begin{tabular}{|ll|}
\hline \multicolumn{2}{|c|}{ Condiciones comunicativas } \\
\hline a) & comunicación privada \\
b) & confianza \\
c) & emocionalidad \\
d) & anclaje en situación y acción \\
& comunicativas \\
e) & posible referencialización desde \\
& aquí y ahora del hablante \\
f) & proximidad física \\
g) & fuerte cooperación \\
h) & carácter dialógico \\
i) & espontaneidad \\
j) & libertad temática \\
k) & etc. \\
\hline & \\
\hline Estrategias de verbalización \\
\hline - & contextualización \\
& extralingüística, gestual, mímica, \\
& etc. \\
- & escasa planificación \\
- & carácter provisional \\
- & sintaxis agregativa \\
- & etc. \\
\hline
\end{tabular}

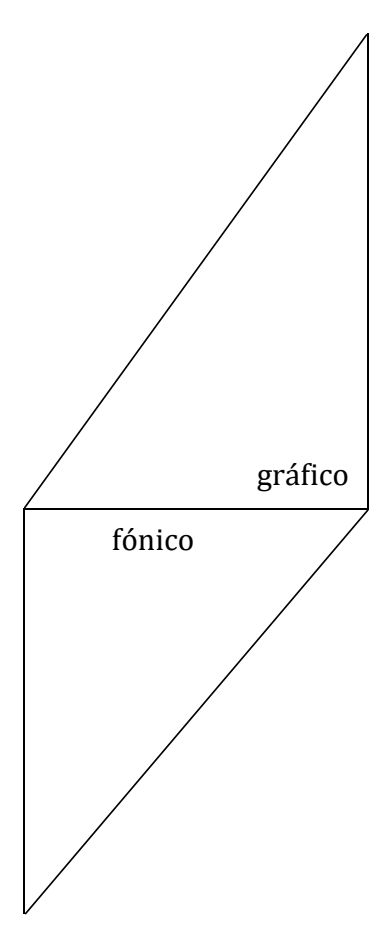

Distancia

\begin{tabular}{|c|}
\hline Condiciones comunicativas \\
\hline $\begin{array}{l}\text { a') comunicación pública } \\
\text { b') desconocimiento } \\
\text { c') ninguna emocionalidad } \\
\text { d') independencia de la situación } \\
\text { acción comunicativas } \\
\text { e') imposible referencialización } \\
\text { desde el aquí y ahora del } \\
\text { hablante } \\
\text { f') distancia física } \\
\text { g') débil cooperación } \\
\text { h') carácter monológico } \\
\text { i') reflexión } \\
\text { j') fijación temática } \\
\text { k') etc. }\end{array}$ \\
\hline Estrategias de verbalización \\
\hline $\begin{array}{ll}\text { - } & \text { contextualización lingüística } \\
\text { - } & \text { alta planificación } \\
\text { - } & \text { carácter definitivo } \\
\text { - } & \text { sintaxis integrativa } \\
\text { - } & \text { etc. }\end{array}$ \\
\hline
\end{tabular}


Por lo que concierne a la rentabilidad de esta modelización de la situación comunicativa para la delimitación de formas de variación no situacional, sino discursiva, a pesar de que no es este el propósito principal de los parámetros enumerados por Koch y Oesterreicher (obsérvese que no se incluye entre ellos la consideración de la finalidad de la comunicación, que la bibliografía es unánime en considerar determinante para la identificación de géneros o tipos de textos), es obvio que cualquier forma de comunicación imaginable $(\mathrm{y}$, por tanto, también las formas prototípicas de los géneros y de las td que son géneros) está necesariamente caracterizada por un haz de valores paramétricos de estas condiciones comunicativas concretas:

Der Erwerb diskurstraditionellen Wissens zeigt, daß es sich bei Diskurstraditionen um Abstraktionen handelt, die aus ganz bestimmten kommunikativ fundierten Identifizierungs-, Konstantisierungs-, Habitualisierungsund Legitimierungs-prozessen resultieren. [...] Wir können hiermit [...] Diskurstraditionen bestimmen als konventionalisierte Kristallisationskerne von bestimmten Parameterwerten der oben skizzierten Kommunikationsbedingungen und mehr oder minder strikt vorgeprägten Versprachlichungsanforderungen einerseits sowie von bestimmten gesellschaftlich determinierten inhaltlich-thematischen Wissenskomplexen andererseits (Oesterreicher 1997: 24; cf. también Koch 1997: 56-57).

[La adquisición del saber discursivo-tradicional muestra que las tradiciones discursivas son abstracciones que resultan de procesos comunicativos muy específicos de identificación, constatación, habitualización y legitimación. [...] A este respecto, podemos [...] definir las tradiciones discursivas como formas prototípicas convencionalizadas en las que han cristalizado ciertos valores de los parámetros de las condiciones de comunicación descritos anteriormente, así como, por un lado, requisitos de verbalización más o menos estrictamente predefinidos, $\mathrm{y}$, por otro lado, conocimientos socialmente determinados en cuanto a su contenido y temática (la traducción es mía)].

De acuerdo con estos planteamientos, Koch y Oesterreicher (1990[2007]: 28-29; ahora también 2011: 8-9) solían poner como ejemplos de moldes discursivos diferenciables por sus distintas configuraciones situacionales, los valores paramétricos de la carta privada, el sermón y la entrevista personal.

Fig. 7. Valores paramétricos comunicativos de la carta privada (apud Koch y Oesterreicher 1990[2007]: 28)

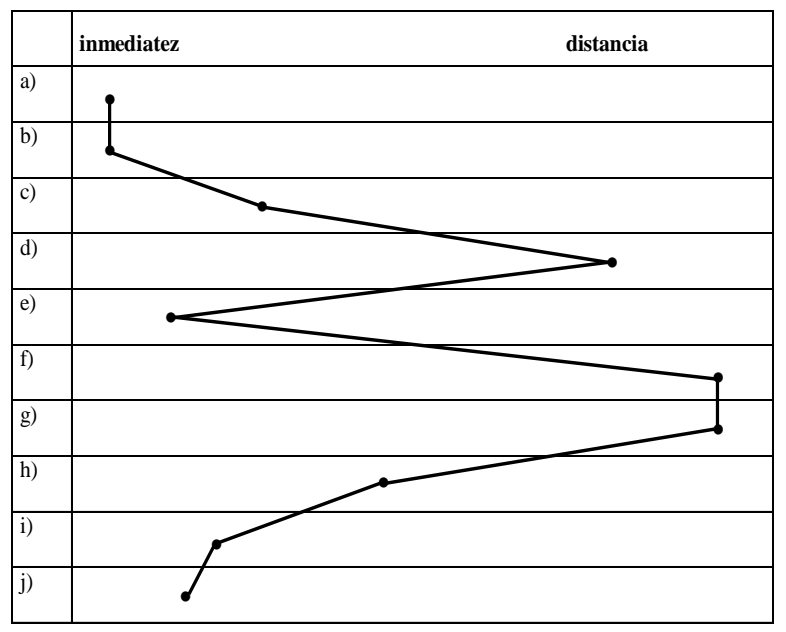


Sin embargo, no obstante la rentabilidad de estas posibles caracterizaciones para discursos particulares, es decir, para el nivel individual del análisis, el hecho de proponer conjuntos de valores paramétricos fijos para las TD, concebidas como formas textuales de carácter histórico, no está exento de problemas. El argumento crucial en este sentido es el reconocimiento de que lo propio de las TD que son géneros es permitir, en su realización individual, diferentes posibilidades de variación concepcional -y diasistemática- en su interior. Y es que, como bien advertía Bajtín (1979[1982/200311]: 269), "existen formas elevadas, estrictamente oficiales de [los] géneros, junto con las formas familiares de diferente grado y las formas íntimas (que son distintas de las familiares)"29.

Para Koch y Oesterreicher, la variación situacional que tiene cabida en el espacio comprendido entre la máxima inmediatez y la máxima distancia comunicativas puede ser (i) de carácter universal, y dar lugar a un tipo de variación que ellos denominan concepcional (dimensión 1a en la fig. 8 infra) o (ii) de carácter histórico, y dar lugar a un tipo de variación, asimismo, concepcional (dimensión 1b en la fig. 8 infra) o a la variación que generalmente se conoce como diafásica o de registro (dimensión 2 en la fig. 8 infra). Esta diferenciación se refleja con mucha claridad en el modelo de la cadena de variedades:

Fig. 8. La cadena de variedades (apud Koch y Oesterreicher 1990[2007]/2011²: 17)

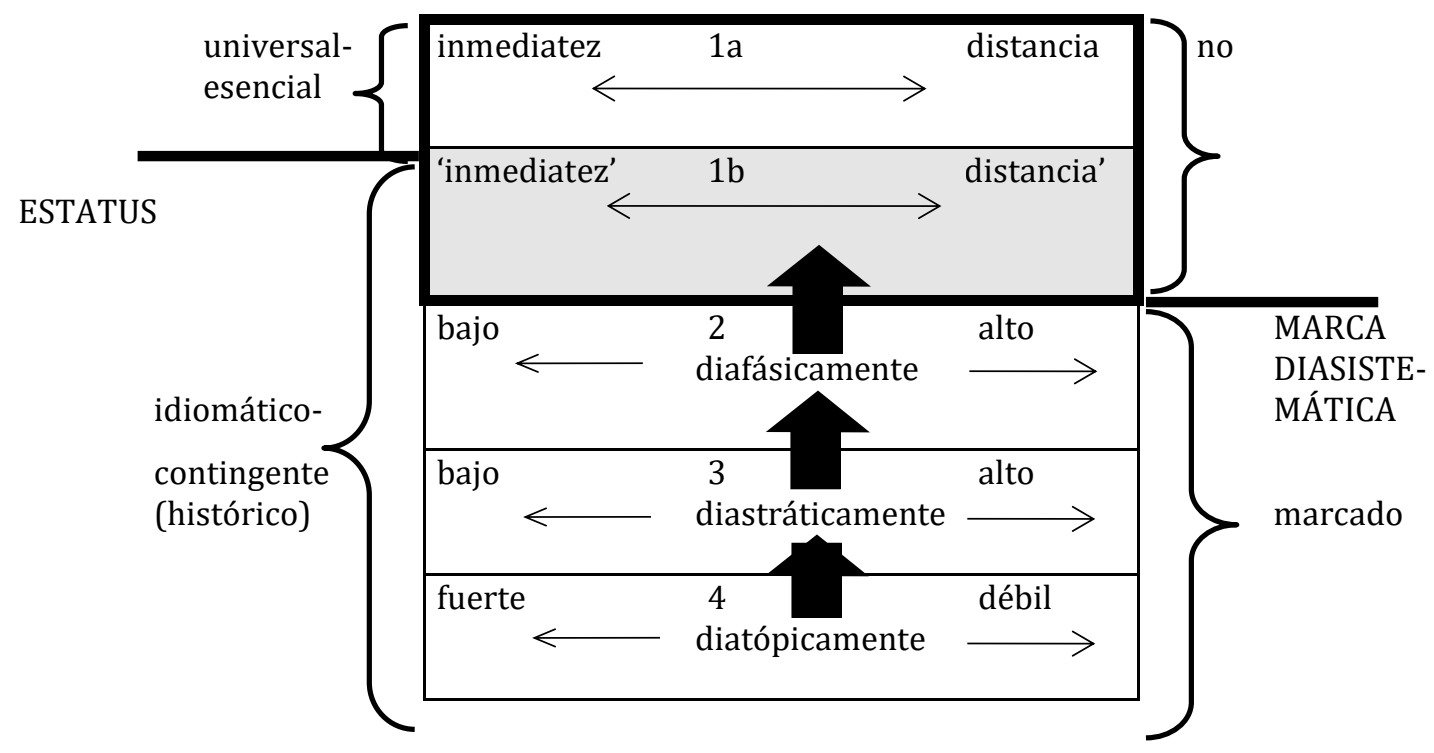

Las modalidades que resultan de la variación concepcional, que se sitúan en el nivel universalesencial del modelo de la cadena de variedades (1a), y a las que en estas páginas se ha hecho referencia, en su delimitación situacional o externa, mediante la expresión perfiles concepcionales $^{30}$, son, pues, de naturaleza universal y competencia del saber elocucional (cf. supra fig. 1). Los fenómenos de variación concepcional de carácter histórico, así como los registros o las variedades diafásicas, sin embargo, son variedades idiomáticas que pertenecen al saber idiomático, de carácter histórico y que, en el modelo de la cadena de variedades, se sitúan en el nivel idiomático-contingente y, dentro de él, en las filas 1 b y 2 del modelo, puesto que en las filas 3 y 4 se ubican las variedades diastráticas y diatópicas, que también son de naturaleza histórica. Así es como la lingüística de las variedades de filiación coseriana mantiene sistemáticamente en sus categorizaciones la distinción entre el nivel universal y el nivel histórico del análisis lingüístico. 
¿Qué ocurre, sin embargo, con la distinción entre la variación debida a los diferentes tipos de circunstancias y la variación vinculada con los diferentes modos de estructurar los discursos? En este segundo caso, como ha quedado señalado más arriba, no ha interesado mantener una distinción nítida. Y, sin embargo, es necesario advertir que, por más que sea posible tender puentes entre las circunstancias que determinan la variación situacional y los contextos en que se recurre al empleo de determinados géneros o TD, ni la figura 6, que aprehende la oposición gradual entre la inmediatez y la distancia comunicativas, ni el modelo de la cadena de variedades, que se ha reproducido en la figura 8 , contemplan la variación textual históricamente determinada $y$, de hecho, en relación con las TD que son géneros o moldes textuales, es posible que para cada molde textual históricamente dado haya que prever la existencia, en su realización individual, de una variación interna similar a la que manifiesta el modelo de la cadena de variedades (aunque tal variación, dependiendo de los géneros o TD implicados, no sea siempre de espectro tan amplio como el que conforma el modelo en su conjunto).

En efecto, como advierte Oesterreicher (1997: 30) - y se argumenta también en Kabatek (2012) - , hay que considerar la necesidad de prestar atención al tipo de cambio lingüístico que consiste en una evolución histórica, bien hacia la inmediatez, bien hacia la distancia, de las td particulares que estén en funcionamiento, en diferentes comunidades socioculturales, para la realización de determinados fines comunicativos:

Fig. 9. Las tradiciones discursivas entre inmediatez y distancia (Kabatek 2012: 92)

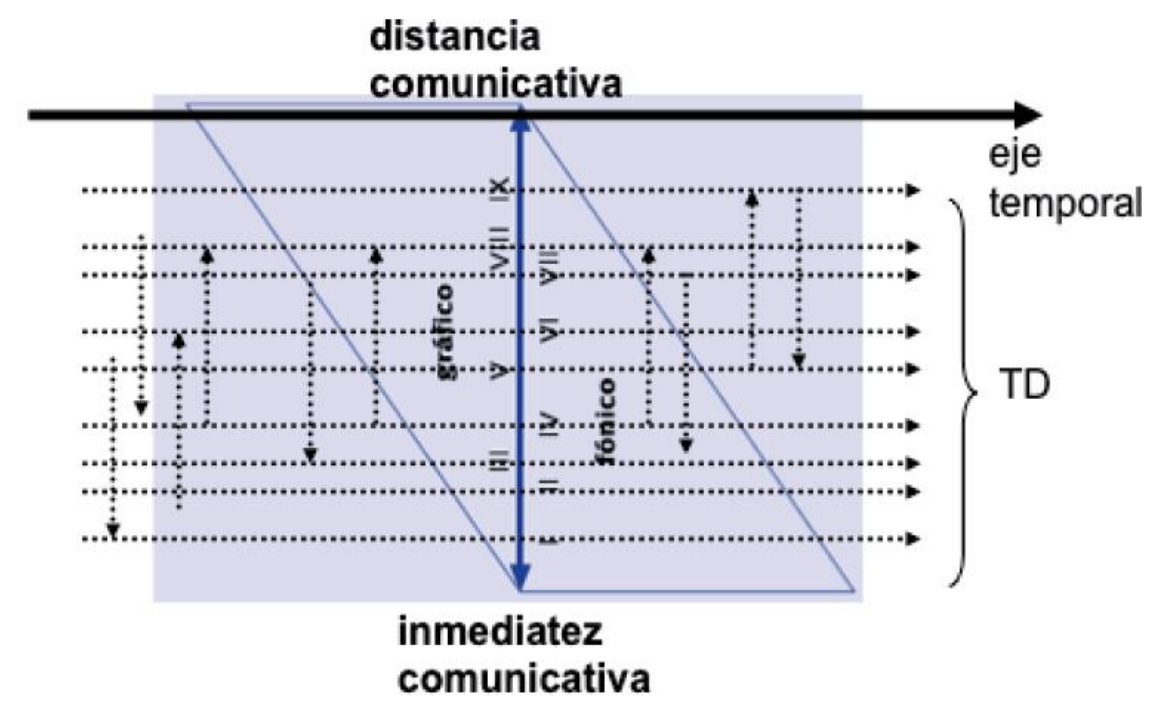

Así las cosas, desde el punto de vista de la categorización teórica, en el nivel histórico del lenguaje parecería necesario distinguir, dentro de toda la gama de posibles TD en sentido amplio que hemos visto que contemplaba Koch, entre, por una parte, las específicamente referidas a los modos de estructurar los discursos, que podríamos seguir llamando géneros o también TD en sentido estrecho, y, por otra, las específicamente referidas a la variación situacional, en relación con las cuales se suele hablar de registros o de variedades diafásicas, según las diferentes tradiciones teóricas. Dicho de otro modo, desde el punto de vista de la teorización lingüística, si partimos de la definición amplia de TD esbozada por Kabatek (2005a), parecería conveniente diferenciar, tal y como se adelantó en $\S 3$, entre, por un lado, la repetición de textos o de formas textuales, que 
pertenecería a la variación discursiva y dispondría de sus propios objetos de estudio — los modos de estructurar ciertos tipos de discursos, entre ellos las TD en sentido estrecho-, y, por otro, la repetición de maneras particulares de escribir o de hablar, que quedaría vinculada al estudio de la variación situacional, y cuyos objetos de estudio serían los modos de hablar en tipos de circunstancias o registros, que quedarían fuera de la definición de TD en sentido estrecho.

A fin de aplicar sistemáticamente la distinción entre las dimensiones universal e histórica del saber expresivo y la diferenciación entre la variación situacional derivada de los distintos tipos de circunstancias en que tiene lugar la comunicación y la variación discursiva relacionada con los diversos modos de estructurar los discursos, en López Serena (2012) se propuso considerar de manera diferenciada cuatro nociones: los modos discursivos, los géneros $-\mathrm{o}$ TD en sentido estrecho, si estas se vinculan únicamente con el ámbito de la variación textual y no de la situacional-, los perfiles concepcionales y los registros o variedades diafásicas, de acuerdo con el esquema que se refleja en la figura 10:

Fig. 10. Variación discursiva vs. variación universal

\begin{tabular}{|l|l|l|}
\hline & VARIACIÓN DISCURSIVA & VARIACIÓN SITUACIONAL \\
\hline NIVEL UNIVERSAL & Modos discursivos & Perfiles concepcionales \\
\hline NIVEL HISTÓRICO & $\begin{array}{l}\text { Géneros (o tradiciones } \\
\text { discursivas en sentido } \\
\text { estrecho) }\end{array}$ & $\begin{array}{l}\text { Registros o variedades } \\
\text { diafásicas }\end{array}$ \\
\hline
\end{tabular}

De acuerdo con este planteamiento, los modos discursivos se conciben como posibilidades universales de la actuación lingüística, determinadas fundamentalmente por la finalidad de la interacción comunicativa, y que se estipulan con un nivel de abstracción tan alto como para constituir, efectivamente, universales antropológicos. Por su parte, los géneros o TD en sentido estrecho se interpretan como modelos históricos para la construcción y la interpretación de discursos $^{31}$. En lo tocante a la variación situacional, se contemplan, por una parte, fenómenos propios de la variación concepcional, producto de las diferentes combinaciones posibles de rasgos universales propios de la situación de comunicación, que requieren estrategias de verbalización adecuadas a tales circunstancias específicas de la enunciación, dependiendo de si nos hallamos más o menos próximos a la máxima inmediatez o a la máxima distancia comunicativa y, por otra parte, registros o variedades diafásicas, constituidos por formas idiomáticas históricas específicas, cuya aparición en situaciones comunicativas determinadas está relacionada, no obstante, con parámetros universales de la variación, como los que permiten establecer los distintos tipos de constelaciones comunicativas posibles entre los polos extremos de la máxima inmediatez y la máxima distancia comunicativa (claro que también estos parámetros favorecen la aparición de rasgos sociolectales y dialectales específicos, no lo olvidemos).

Así, tendríamos cuatro conceptos relevantes para el estudio de la variación inherente a la competencia lingüística y, por tanto, al saber expresivo, dos referidos al carácter universal de ciertos principios o configuraciones necesarias en la producción discursiva, así como de ciertos esquemas de verbalización característicos de determinadas constelaciones comunicativas estipuladas a partir de parámetros universales (los modos del discurso y la variación concepcional de carácter universal) y dos referidos a los cauces históricos específicos que condicionan el saber textual socioculturalmente específico de los hablantes de distintas comunidades (idiomáticas o 
supraidiomáticas): el dominio de la variación diafásica, vinculado con el saber idiomático ${ }^{32}$, y el conocimiento de los modelos textuales tradicionales de los que los hablantes de diferentes ámbitos sociohistóricos se valen para producir muestras de los diferentes géneros que su actividad comunicativa precise en cada momento, que sería el propio de las TD en sentido estrecho (no a las TD latu sensu, que abarcarían todas las formas históricas de la figura 9).

Es obvio que categorías como las anteriores, "pese a la rentabilidad metodológica de su disociación, resultan en la práctica realidades indivisas" (Pons Rodríguez 2008: 200), por lo que en muchos casos será difícil distinguir con claridad qué pertenece al modo discursivo universal, qué a la $T D$, qué al registro y qué a la variación concepcional, pero si se adopta un enfoque de objeto de estudio, es imperativo que la diferenciación teórica de ámbitos de variación distintos esté bien delimitada, al menos, como horizonte de la investigación.

\section{LAS TRADICIONES DISCURSIVAS COMO MATERIA DE ESTUDIO}

Como se ha evidenciado en distintos momentos de este artículo, el enfoque de objeto de estudio no es el único posible. Hay autores que adoptan un enfoque de materia de estudio y se interesan, no por la categorización teórica que construye distintos tipos de variedades lingüísticas, sino por la descripción de la variación lingüística ${ }^{33}$. Estos especialistas, entre ellos muchos historiadores de la lengua, recurren a la noción de TD como herramienta para el análisis filológico, porque comparten, con esta perspectiva de estudio, la convicción de que no es posible trabajar en lingüística histórica al margen de la consideración de todos los factores discursivo-tradicionales que hacen problemática la interpretación de los datos lingüísticos al margen de la observación del tipo de contexto discursivo-tradicional en que estos datos aparezcan (cf. supra § 2, n. 9 y $\S 3$, e infra n. 39). Para ellos, por lo general, las distinciones que se establecen en la figura 9 carecen de interés ${ }^{34}$. De hecho, si efectuamos una breve cala en los estudios de historia de la lengua española que se hacen eco del término $T D$, el análisis semasiológico corrobora que, en este ámbito, que como hemos dicho opera con una óptica de materia de estudio, es frecuente rehuir las categorizaciones teóricas rigurosas. Así las cosas, en este tipo de estudios es habitual que el término TD aparezca de una forma absolutamente tangencial, es decir, sin que entre los propósitos del trabajo en que se hace uso de él figuren objetivos de investigación relacionados con la comprobación de en qué medida un determinado fenómeno de cambio lingüístico o un determinado hecho lingüístico atestiguado en un estado de lengua pretérito pueda haberse visto propiciado o inhibido por condicionantes de naturaleza discursivo-tradicional ${ }^{35}$. Esta tendencia fue observada ya por Martha Guzmán en un artículo de 2007, en el que esta autora hablaba de

trabajos recientes que, aunque mencionan e incluso dicen prestar especial atención a las tradiciones discursivas, no pasan de su mera mención, se basan en adscripciones apresuradas, se concentran en el estudio de elementos de dichas tradiciones cuya relevancia es, cuanto menos, oscura, o comparan textos de diferentes tradiciones como si de estructuras monolíticas se tratara (Guzmán Riverón 2007: 87; la cursiva es mía).

Tal y como ponía de relieve Guzmán, abundan, efectivamente, las publicaciones en las que el término se utiliza de una forma rayana en lo meramente ornamental, lo que nos lleva a confirmar que esta etiqueta se ha convertido en el lugar común por excelencia de los actuales estudios de 
lingüística histórica del español. Así, es frecuente exhortar a explorar un determinado corpus desde el punto de vista de las TD:

\begin{abstract}
El corpus es un instrumento particularmente apto para el estudio de una cuestión, sin duda fundamental, la cual ha sido materia de importantes contribuciones, la de la formación de tradiciones discursivas. Aquí no puedo pretender siquiera una incursión en este interesante complejo temático, pero sí puedo asegurar que la variedad temática y estilística de los textos, la diversidad de escribientes de distintos niveles y con distintas competencias, la variación en cuanto a opciones sintáctico-semánticas y pragmáticas, hacen de este corpus, y especialmente con miras a una caracterización del diasistema subyacente, una fuente que permitirá aportes importantes en esta materia; cursiva original (Rivarola 2012: 395),
\end{abstract}

o aventurar la posible relación que un determinado fenómeno pueda tener con factores de naturaleza discursivo-tradicional, pero no ir más allá de esta sugerencia, como ocurre por ejemplo en el trabajo de Miriam Bouzouita del que procede la siguiente cita; un trabajo en el que se apela a la posible influencia de la TD como factor explicativo de las diferencias que distintos autores han hallado en un mismo conjunto de unidades lingüísticas cuyo comportamiento morfosintáctico difiere en textos de una misma época, sin que esta posible influencia se llegue realmente a investigar:

los resultados de nuestro corpus parecen apuntar a conclusiones distintas de las que saca Company Company. Aunque no dudamos de la exactitud ni de la relevancia de las observaciones de esta autora para su corpus, podemos concluir que estos resultados no parecen extrapolarse a otros corpus y, por lo tanto, que la selección de la primera o segunda persona por los PA [pronombres átonos] no parece ser un rasgo característico de los FA [futuros analíticos] en general. Probablemente hay otros factores que incluyen en esta selección, como por ejemplo los relacionados con la tradición discursiva (Bouzouita 2012: 699; la cursiva es mía).

A veces se menciona, bien la noción, bien el marco teórico de las TD —incluso ambas cosas-, pero no se precisa en qué sentido concreto este enfoque podría arrojar luz sobre el objeto de estudio en que se centra un determinado trabajo, sino que más bien se siente la necesidad de advertir al lector que se ha investigado un determinado fenómeno o cambio lingüístico, como dicen M. a del Mar Espejo y Rosa Espinosa (2012: 750), "sin olvidar el influjo [de] las tradiciones discursivas"36.

Otras veces se intuye la necesidad de advertir - y ello nos corrobora que estamos ante un lugar común- de que se es consciente de haber mezclado en un estudio diferentes TD:

Aparte de las bienvenidas críticas que se le pueden hacer a nuestro trabajo, tales como que no analiza sino que describe (lo cual es fácilmente cuestionable teniendo en cuenta que desde el momento mismo en que el filólogo establece una teoría sobre la que basar su análisis está interpretando) y que mezcla tradiciones discursivas al colocar en un mismo estudio textos notariales, albalás, certificados de matrimonio y misivas reales (lo cual es plenamente cierto, pero irrelevante, a nuestro entender, para los objetivos de este artículo), es posible llegar a algunas conclusiones iniciales (Fernández Martín 2012: 803; la cursiva es mía).

Frente a este panorama semasiológico sin duda ingrato para los espíritus más teóricos, si cambiamos radicalmente la perspectiva y adoptamos un punto de vista onomasiológico, nos encontraremos con estudios en los que no se hace mención alguna al concepto de TD, pero en los que sí se atiende a la "influencia que poseen las estructuras discursivas propias de cada tipo de discurso respecto del valor que adquieren los fenómenos lingüísticos testimoniados en cada uno 
de los tipos de texto" (Bustos Tovar 2003: 1859). Y es que, como señalaba también Martha Guzmán en la misma publicación que se ha citado anteriormente, "no escasean ejemplos de estudios [...] en los que, sin hacer mención [...] a la expresión tradiciones discursivas, sí se tienen en cuenta éstas" (Guzmán Riverón 2007: 87). De hecho, como afirmaba en 2012 Johannes Kabatek, en relación con la pregunta "¿Por qué esta convicción de la necesidad de la distinción de tradiciones discursivas en sintaxis histórica?": hay que tener en cuenta que

de algún modo siempre se ha sabido y se ha comentado que la variación sintáctica depende en gran medida de la tradición textual, y eso tanto si consideramos el texto en su totalidad como cuando lo diferenciamos internamente. Así, por ejemplo, George Trager señaló en los años treinta del s. xx que la frecuencia de los demostrativos latinos variaba considerablemente según las características de los pasajes textuales, y que encontramos usos del demostrativo interpretables como artículo por ejemplo en el Itinerarium Egeriae sobre todo en pasajes que destacan eventos mientras que están ausentes en los pasajes narrativos correspondientes a otra tradición discursiva (Kabatek 2012: 91; la cursiva es mía)37.

Pese a que, como ya se advirtió en $§ 2$, en los estudios de historia del español el uso del concepto TD no sea unívoco y aunque, como también se señaló en la introducción ( $(1)$, la consulta de los trabajos fundacionales de esta corriente de investigación (Koch 1987, 1997; Oesterreicher 1997; Jacob y Kabatek 2001; Kabatek 2001, 2005a[2018]) tampoco desemboque en la obtención de una única definición de consenso ${ }^{38}$, dentro del paradigma de las TD sí hay acuerdo en aspectos de naturaleza terminológico-conceptual, como el hecho de que la relación entre los conceptos género textual/discursivo y tradición textual/discursiva no es de sinonimia. Y también lo hay en aspectos de índole metodológica, como el rechazo, al que se ha hecho referencia en más de una ocasión a lo largo de estas páginas, a una lingüística de corpus ciega frente a los factores discursivotradicionales que influyen en la interpretación de cualquier dato lingüístico y que propugne una visión del cambio lineal ${ }^{39}$.

Por lo que respecta a la imposibilidad de entender como sinónimos los términos género textual/discursivo y tradición textual/discursiva, esto se debe a que, si bien todo género es, en efecto, una TD, como señala Wulf Oesterreicher, no todas las TD comparecen, necesariamente, en forma de géneros:

[L]as variedades lingüísticas de una lengua tienen una afinidad con determinados usos en situaciones comunicativas […]. Estas situaciones se cristalizan en lo que, a veces, se denomina 'géneros textuales' o 'tipos de texto' y que yo prefiero llamar 'tradiciones discursivas'. En primer lugar, para enfatizar la dinámica interna de estos modelos discursivos históricos[;] en segundo lugar, para evitar la identificación con una teoría literaria de los géneros; en tercer lugar, para distanciarnos de los intereses y procedimientos puramente clasificatorios de la llamada tipología textual; y en cuarto lugar, porque las tradiciones discursivas no se corresponden necesariamente con modelos textuales enteros, sino que pueden ser caracterizadas también por ciertos rasgos lingüístico-estilísticos que se emplean en diferentes géneros de perfil concepcional comparable (Oesterreicher 2012: 231-232; la cursiva es nuestra; cf. también Kabatek 2005a[2018]: 156).

Sin embargo, esta falta de equivalencia entre los conceptos género textual/discursivo y tradición textual/discursiva, que especialistas poco sospechosos de comulgar con el marco de las TD como Manuel Ariza daban por consabidas ${ }^{40}$, no ha sido tan evidente para otros autores, que han utilizado con profusión el término $T D$ como mera variante expresiva de género. Los casos más claros de equiparación entre géneros, tipos de texto y TD que ofrecen los estudios de historia de la lengua española son pasajes como los siguientes, en los que alguno de los tres términos implicados (género, tipo de texto o 
tradición discursiva, con variantes como clase de texto o tipo textual) recupera, en un determinado contexto, de forma anafórica cualquiera de los otros dos.

\begin{abstract}
Me he fijado en el análisis de una tradición discursiva bien delimitada, la prosa científica, también denominada tratadística científico-técnica o género de divulgación científica, y en el período histórico en el que arranca la producción del tipo de textos que en ella se incluyen (Porcar Miralles 2012: 249; la cursiva es mía).

Los conceptos de texto/discurso han desarrollado, como vía de trabajo, el análisis de los modelos tradicionales de expresión, y se habla de tradiciones discursivas. En este intento de describir y clasificar los tipos de textos, hay que considerar los antecedentes, y ver cómo han evolucionado hasta llegar a lo que hoy consideramos tipo narrativo, descriptivo, argumentativo, etc. (Hoyos Hoyos 2012: 2243; la cursiva es mía).

Otra de las cuestiones que se han planteado en relación con la teoría de la gramaticalización es la relativa a la necesidad de dar cabida a las tradiciones discursivas $[\cdots]$. En general, los estudios sobre gramaticalización han optado por un enfoque que no distingue tipos de texto, de manera que la descripción de la evolución de las estructuras gramaticales puede resultar distorsionada, ya que, a menudo, la aparición de una construcción o de una palabra gramatical queda ligada en sus orígenes a una tradición discursiva determinada (Garachana Camarero 2015: 346; la cursiva es mía).
\end{abstract}

En todos estos casos, el uso, aparentemente intercambiable, de los términos género y tradición es perfectamente compatible con la concepción fundacional de las TD de acuerdo con la cual, tal y como hemos advertido, los géneros son TD, pero hay también TD que no constituyen, por decirlo con las mismas palabras que hemos visto que empleaba Wulf Oesterreicher en la cita de este autor que se ha reproducido más arriba, "modelos textuales enteros". De hecho, en la bibliografía abundan los pasajes en los que, si bien no es posible concluir que un determinado autor entienda las expresiones tipo de texto, género y tradición discursiva como sinónimas, tampoco se puede decir que se haya esforzado por delimitarlas sistemáticamente en todos sus contextos de aparición. Esto es lo que ocurre, por ejemplo, cuando Jacob y Kabatek (2001: viii) señalan que la generalización de una lengua como medio de comunicación en cualquier situación comunicativa durante su proceso de elaboración lingüística "presupone que sea capaz de producir cualquier género textual o tradición discursiva, y, sobre todo, que desarrolle y ponga a disposición las técnicas discursivas y lingüísticas precisas para cualquiera de estos géneros y situaciones" (la cursiva es mía); cuando López Serena (2007: 49) afirma que “[1]a cuestión de las tipologías textuales y los géneros o tradiciones discursivas goza de una creciente popularidad en la lingüística actual" (la cursiva es mía), o cuando Garcés Gómez, al hilo de la exposición de los objetivos de un proyecto de investigación dirigido por ella, escribe:

Para emprender esta tarea es fundamental contar con una base documental apropiada y adecuada a nuestras necesidades. En este aspecto, disponemos de diversos corpus que serán la base de nuestro trabajo. Un corpus de datos seleccionado para el análisis de la lengua en los Siglos de Oro, lematizado y etiquetado, que HA SIDO ELABORADO A PARTIR DE OBRAS REPRESENTATIVAS DE LOS DISTINTOS GÉNEROS Y TRADICIONES DISCURSIVAS (Garcés Gómez 2012: 2691; la versalita y la cursiva son mías).

Ahora bien, como señala Octavio de Toledo (2018: 118), "si las TD no fueran más que una forma de referirse a (las manifestaciones particulares e históricamente cambiantes de) los géneros, su utilidad descriptiva resultaría limitada, pues es perfectamente posible presentar las relaciones entre grupos de textos afines $[\ldots]^{41}$ sin acudir al concepto de TD”. Si en el debate entre género frente 
a TD no estamos ante un mero capricho terminológico es, en opinión de este autor, al menos por tres razones:

De entrada, las TD son entidades lingüísticas, pero no unidades específicas de la Lingüística (ni siquiera en el marco de una Lingüística del Texto), sino que su carácter es más ampliamente semiótico (cf. Kabatek 2005a, 2011)[42]: es lingüística, claro está, su manifestación, pero su valor como símbolos significantes se desenvuelve en el contexto general de las formas sociohistóricamente determinadas de la comunicación humana ${ }^{43}$; de ahí que se consideren TD las fórmulas de saludo, despedida o juramento, así como, en un ámbito de interacción muy distinto, las jergas urbanitas (berliner Schnauze, cockney, cheli...), que no son, en sentido estricto, dialectos ni sociolectos (y menos aún géneros), sino, si acaso, registros (en el sentido de Halliday y Hasan 1985; cf. Lukin et al. 2011) históricamente cristalizados (Octavio de Toledo 2018: 118).

En segundo lugar, una TD, en la medida en que no es sino un signo que establece un vínculo entre el código lingüístico y las prácticas culturales concretas, puede relacionarse con otros signos semejantes (otras TD) de manera simultánea y combinarse con ellos composicionalmente (cf. Kabatek 2015a): puede contener a dichos signos o ser parte de ellos, y también solaparse parcialmente con ellos, ya en la forma, ya en el contenido, lo cual dificulta su categorización mediante agrupaciones taxonómicas, como lo son característicamente, en cambio, las de la investigación en torno a la noción de género (Octavio de Toledo 2018: 118-119).

En tercer lugar, una TD escritural no es necesariamente un texto o grupo de textos[…: puede desenvolverse muy por debajo del nivel textual, ser una técnica constructiva o incluso una construcción o un elemento lingüístico concretos siempre que cumpla con las condiciones generales de significación exigibles a una TD, que no es otra cosa que "la repetición de un texto o de una manera particular de escribir o de hablar que adquiere valor de signo propio [...]" (Kabatek 2005a: 157) (Octavio de Toledo 2018: 119).

A este último respecto es importante resaltar que la etiqueta $T D$ se utiliza, con frecuencia, ya no exactamente como término equivalente al de género discursivo, tipo de texto o género textual, sino, sobre todo, como expresión extraordinariamente imprecisa de extensión a veces más amplia y a veces más restringida que la del concepto de género. Esto tiene que ver con algo sobre lo que también advierte Octavio de Toledo:

Si las TD se avienen mal con las tipologías clasificadoras, es evidente su utilidad, en cambio, para dar cuenta de las convergencias e hibridaciones entre (clases de) textos que con frecuencia se encuentran en el origen de la cristalización de nuevos géneros a lo largo de la historia. Para el investigador diacrónico, pues, una parte no desdeñable de la utilidad descriptiva de las TD reside en la capacidad de asociar a través de ellas, mediante semejanzas de forma o contenido, géneros (o subgéneros, o macrogéneros) no necesariamente emparentados de forma genética ni pertenecientes al mismo taxon, sino conectados mediante redes de "parecido de familia", cuyos miembros solo necesitan poseer al menos un rasgo común con aquellos a los que se encuentran inmediatamente asociados. Ello permite un acceso intuitivo a las asociaciones entre géneros de innegable potencial heurístico, especialmente en perspectiva histórica (Octavio de Toledo 2018: 119, n. 36).

\section{CONCLUSIONES}

Debido a la laxitud de las definiciones extensiva e intensiva del concepto de TD con que se opera en los estudios que adoptan una perspectiva de materia, algunos autores se han dolido de que en este ámbito ocurra algo parecido a lo que Rafael Cano señalaba, a finales de los años 90, en relación con la variación oral/escrito: Se "maneja[n] con excesiva soltura conceptos que la Lingüística actual trata de precisar para su adecuada utilización" (Cano Aguilar 1998: 20). Incluso es posible 
que hayamos llegado al punto de poder parafrasear a Javier Elvira cuando hace unos años, a propósito de otra noción clave en la actual lingüística histórica, la de gramaticalización, afirmaba:

el concepto de gramaticalización está un poco devaluado por un uso "inflacionario" en los estudios de lingüística y gramática de los últimos años. [...] la noción de gramaticalización se ha convertido en una especie de comodín al que muchos investigadores recurren cuando quieren hacer referencia a muy variados procesos de innovación gramatical. De ahí el escepticismo con el que algunos contemplan el concepto (Elvira González 2012: 315$)^{44}$.

Tomando prestadas las anteriores palabras de Javier Elvira, quizás sea obligado admitir que el concepto de TD está, a día de hoy, un poco devaluado por un uso inflacionario y que el término se ha convertido en una especie de comodín al que muchos investigadores recurren cuando quieren hacer referencia a muy variados aspectos de la variación textual o discursiva, incluso a la variación diafásica; de ahí el escepticismo que este concepto pueda llegar a generar. Ahora bien, si tal escepticismo podría tener sentido para quienes adoptan una óptica de objeto de estudio, es decir, para quienes procuran diseñar categorías teóricas lo más precisas y rigurosas posibles (cf. Zamorano Aguilar 2020), que el término TD se haya convertido en una especie de comodín para los historiadores de la lengua en absoluto tiene por qué ser un problema, sobre todo si se tiene claro que estos estudiosos no recurren a él como objeto de estudio, sino por su "innegable potencial heurístico" 45 para las indagaciones acerca de los fenómenos de tradicionalidad discursiva que investigan como materia de estudio.

Sin duda, la selección de dos términos absolutamente transparentes de la lengua común (el término tradición y el término discursivo) como base para la acuñación de este tecnicismo ha contribuido a que todos los lingüistas que lo han incorporado a su vocabulario lo utilicen como buenamente lo interpreta cada uno de ellos, en muchos casos, como sinónimo de género o tipo de texto46. Con todo, aparte de por el arraigo del término $T D$ en la lengua común, los problemas de delimitación unívoca del concepto y el uso indistinto de TD y género que se observa que prolifera en la bibliografía -y que, insisto, constituye un problema solo para los enfoques teóricos de objeto de estudio, no para los descriptivos de materia de estudio - ha venido propiciado por otra serie de circunstancias. En primer lugar, por el hecho de que el marbete $T D$ se emplea a menudo sin que se proporcione definición alguna del concepto y/o sin que se remita a ninguna de las definiciones propuestas por los autores responsables de su acuñación original ${ }^{47}$. En segundo lugar, porque tampoco es inusual que incluso haciéndose referencia a alguna de las definiciones existentes que en ocasiones hasta se llegan a reproducir literalmente- el contenido de tales definiciones se contradiga a renglón seguido de su citación. En este sentido, mi impresión es que, como todos sabemos qué significa tradición en la lengua común y también parecemos saber qué significa discurso, todos creemos entender perfectamente el sintagma tradición discursiva. A este respecto, conviene recordar que, como se señaló páginas atrás, ni siquiera de la lectura de los trabajos de los autores responsables de la acuñación de esta noción como herramienta teórico-metodológica es posible extraer una definición unánime. Lo que sí es posible - y también se señaló más arribaes detectar tres grandes consensos: (i) el acuerdo en torno al hecho de que la relación entre los conceptos género textual/discursivo y tradición textual/discursiva no es de sinonimia, (ii) la coincidencia en rechazar que la lingüística histórica se convierta en una lingüística de corpus emprendida al margen de la consideración de todos los factores discursivo-tradicionales que hacen problemática la interpretación de cualquier dato lingüístico con independencia de la observación del tipo de contexto discursivo-tradicional en que este dato aparezca y (iii) la adopción de una 
perspectiva metodológica que va de los textos a la identificación de aspectos discursivotradicionales y no de las categorías preestablecidas a los textos48, es decir, de un enfoque de materia.

A mi modo de ver, la preservación de estas dos convicciones en torno a las cuales hay absoluto acuerdo no es incompatible con la ambigüedad que se deriva de haber conformado un tecnicismo mediante la imbricación de dos palabras aparentemente inteligibles de la lengua común cuyo uso terminológico es cualquier cosa menos inequívoco. De hecho, considero que una de las ventajas del uso "inflacionario" del término $T D$ en los estudios de sintaxis histórica del español ha sido precisamente la profundización en la idea de que la lingüística histórica no puede ser nunca una lingüística de corpus emprendida al margen de la consideración de todos los factores discursivotradicionales que intervienen en la configuración de cualquier texto y que influyen, por tanto, en la interpretación de sus testimonios lingüísticos. A este respecto, me parecen muy significativas las citas de Espejo Muriel y Espinosa Elorza (2012) o de Fernández Martín (2012) que se trajeron a colación en $\S 6$, ya que ambas ponen de manifiesto hasta qué punto esta es una convicción absolutamente extendida entre los historiadores de la lengua española. Recuérdese cómo M. ${ }^{a}$ del Mar Espejo y Rosa Espinosa declaraban no haber olvidado el influjo de las TD y cómo Fernández Martín se anticipaba a las críticas que esperaba recibir por haber mezclado TD.

El éxito del rechazo de una lingüística histórica convertida en una mera lingüística de corpus tiene que ver, naturalmente, con su compatibilidad con el espíritu filológico que está en la base de esos estudios, circunstancia a la que se refería Martha Guzmán cuando hablaba de estudios "en los que, sin hacer mención [...] a la expresión tradiciones discursivas, sí se tienen en cuenta éstas" (Guzmán Riverón 2007: 87) o Kabatek cuando, como también hemos apuntado ya, señalaba que "de algún modo siempre se ha sabido y se ha comentado que la variación sintáctica depende en gran medida de la tradición textual, y eso tanto si consideramos el texto en su totalidad como cuando lo diferenciamos internamente" (Kabatek 2012: 91). Pues bien, una de las características más relevantes de los estudios filológicos es que siempre adoptan una perspectiva de materia y no de objeto de estudio.

Así las cosas, de acuerdo con la línea argumental que se ha seguido en este artículo, la principal conclusión que podríamos extraer de las reflexiones que se han vertido en estas páginas es la siguiente: ni la conversión, en los trabajos de cariz descriptivo que adoptan la perspectiva que hemos denominado de materia de estudio, del marbete $T D$ en una expresión extraordinariamente vaga ni el uso laxo de este término que se aprecia en la bibliografía no específicamente teórica tienen por qué enjuiciarse como problemáticos para esa lingüística que en absoluto necesita precisar la definición de este concepto desde una óptica de objeto de estudio. Con todo, para evitar la confusión que parece conllevar la falta de disociación, en las reacciones frente al uso impreciso del término $T D$, entre enfoques descriptivos o de materia y enfoques teóricos o de objeto, para el primer tipo de aproximaciones, las descriptivas, entiendo que lo óptimo sería prescindir de delimitaciones excesivamente rígidas como las que se han presentado en $\S \S 4$ y 5, e incluso evitar la noción de TD y hablar, como de hecho se lleva haciendo ya algunos años, a instancias, entre otros, del propio Peter Koch, de aspectos de tradicionalidad discursiva o de aspectos discursivotradicionales (cf. Winter-Froemel et al. 2015). Y ello por tres motivos 49.

En primer lugar, tanto el sustantivo abstracto que constituye el núcleo del sintagma tradicionalidad discursiva como el adjetivo discursivo-tradicional tienen, frente al marbete tradición discursiva, la ventaja de dificultar su equiparación exclusivamente con las nociones de 
género y de tipo de texto, así como la de resaltar que estamos ante una propiedad ${ }^{50}$ de los discursos, por lo que se adecuan a la concepción amplia de los moldes textuales de naturaleza histórica basados en el fenómeno de la repetición que adoptan los enfoques descriptivos para los que los aspectos discursivo-tradicionales son parte inherente - esto es, propiedades - de los datos que conforman su materia de estudio.

En segundo lugar, tanto el sustantivo abstracto tradicionalidad como el adjetivo discursivotradicional preservan la idea de que la atención hacia los aspectos discursivo-tradicionales de los textos es consustancial a la investigación en lingüística histórica.

Y, por último, la evitación de la reificación a la que irremediablemente suele abocar la acuñación de términos de naturaleza nominal facilita que, frente a la fiebre taxonómica de aproximaciones formalistas como la de la tipología textual, los estudios interesados en la tradicionalidad discursiva para su aplicación a tareas de descripción, y no de teorización, preserven su vínculo con la metodología filológica tradicional, de cuyos mejores exponentes son dignos herederos. En este sentido, es interesante recordar que, mientras que Kabatek (2008: 11) señala que "[p]or lo menos desde el famoso estudio precursor de Antoni Badia i Margarit (1960) sobre los 'dos tipos de lengua, cara a cara', la mención de las TD —aunque ante litteram - es bien conocida en los estudios de sintaxis histórica del español", Lola Pons interpreta que

[e]l concepto de tradición discursiva [...] resulta [...] especialmente oportuno en una escuela filológica como la española, donde la tradición heredera de Menéndez Pidal y de Lapesa nunca dio gran acogida en los estudios de lingüística histórica al prisma férreamente inmanentista del estructuralismo, y donde la tarea de acercarse a los textos para describir con precisión sus aspectos lingüísticos tenía siempre aparejada una mirada al modo de construcción textual, a los moldes retóricos, al contexto, a la historia cultural y social de una comunidad y a su vinculación con la lengua (Pons Rodríguez 2008: 199; cf. también, a este respecto, Narbona Jiménez 2009: 85).

Abogar en estas páginas por el uso del término tradicionalidad discursiva, en sustitución de la expresión tradición discursiva, en los estudios que asumen una perspectiva de materia y exponer los motivos por los que este tipo de enfoque no puede - ni debe- hacer suyos los propósitos de los abordajes que tienen una perspectiva de objeto quizás genere la falsa impresión de que la perspectiva de objeto, para la que se conserva el concepto de TD y para la que no se propone, por tanto, modificación terminológica alguna, está más próxima al espíritu originario de la propuesta de Peter Koch que la perspectiva de materia. Para evitar malentendidos en este sentido, me gustaría traer a colación, como colofón de estas reflexiones, las siguientes consideraciones de Johannes Kabatek, que proceden de un trabajo en el que se pretende, de algún modo, llamar la atención sobre el hecho de que la perspectiva de materia es la que mejor casa con la verdadera esencia de las TD y en el que Kabatek se muestra de acuerdo con la pertinencia de abrazar, a este respecto, el marbete tradicionalidad discursiva:

Toda la discusión en torno a las tradiciones discursivas adolece, desde mi punto de vista, de un problema de perspectiva. Se parte, en primera instancia, de determinadas categorizaciones de lo repetido o de lo repetible y solo a posteriori se formula la pregunta acerca de cuál es la tradición discursiva que subyace a esos elementos repetidos o repetibles. Ahora bien, desde el momento en que nos situamos en el ámbito de las categorías, obstruimos el propio proceso de categorización. Quizás tenga sentido invocar en este contexto la diferenciación establecida por Peter Koch entre las tradiciones discursivas como entidades y la tradicionalidad discursiva como la propiedad que caracteriza a todo lo que es susceptible de entrañar una dimensión tradicional (Kabatek 2015a: 56; la traducción es mía) ${ }^{51}$. 
Como espero haber puesto de manifiesto en estas páginas, la fecundidad heurística de las nociones tradición discursiva y tradicionalidad discursiva no deriva de la precisión de su establecimiento como categorías teóricas, sino del consenso imperante acerca de su utilidad como herramientas metodológicas ${ }^{52}$. Así las cosas, entiendo que invocar la noción de tradicionalidad discursiva no solo tiene - como señala Kabatek - sentido, sino que podría ahorrarnos los problemas que emergen cuando se confunden, en la discusión, las perspectivas de materia y de objeto de estudio que este artículo ha pretendido delimitar.

\section{Bibliografía}

ARIZA VIGUERA, M. (2012): “El romance en la primera mitad del siglo XIII (documentos notariales castellanos)”, in E. Montero Cartelle (ed.), vol. I, pp. 5-28.

Badia I Margarit, A. (1960): “Dos tipos de lengua cara a cara”, Studia Philologica. Homenaje a Dámaso Alonso. Madrid: Gredos, vol. I, pp. 115-139.

BAJTíN, M. M. (1979[1982/200311]): Estética de la creación verbal. Madrid: Siglo XXI [Versión española del original ruso Estetika slovesnogo tvorchestva. Moscú, 1979].

Bernardo Paniagua, J. M. (1999): “Epistemología e historia de la lingüística”, in Á. López García (ed.): Lingüística general y aplicada. Valencia: Universitat de València, pp. 377-403.

Bouzouita, M. (2012): “Los futuros analíticos y sintéticos en la Fazienda de Ultra Mar”, in E. Montero Cartelle (ed.), vol. I, pp. 695-706.

BOYER, P. (1990): Tradition as truth and communication: a cognitive description of traditional discourse. Cambridge: Cambridge University Press.

Bustos Tovar, J. J. DE (2002): "Mecanismos de cohesión discursiva en castellano a fines de la Edad Media”, in M. a T. Echenique y J. Sánchez Méndez (eds.): Actas del V Congreso Internacional de Historia de la Lengua Española. Madrid: Arco/Libros, pp. 53-84.

Bustos Tovar, J. J. DE (2003): “Los textos literarios en la historia lingüística de Menéndez Pidal”, in J. J. de Bustos Tovar y J. L. Girón Alconchel (eds.): Actas del VI Congreso Internacional de Historia de la Lengua Española (Madrid, 29 de septiembre-3 de octubre de 2003). Madrid: Arco/Libros. vol. II, pp. 1855-1864.

CANo Aguilar, R. (1998): "La sintaxis del castellano primitivo oración compleja y estructura discursiva”, in C. García Turza, F. González Bachiller y J. Mangado Martínez (eds.): Actas del IV Congreso Internacional de Historia de la Lengua Española (La Rioja, 1-5 de abril de 1997). Logroño: Universidad de la Rioja, vol. I, pp. 17-36.

CoSERIU, E. (1956-1957): El problema de la corrección idiomática. Montevideo, manuscrito inédito custodiado en el Archivo Coseriu de la Universidad de Tübingen (Alemania) (www.coseriu.de). Hay una versión actual, en forma de libro, de este trabajo: Coseriu, E. 2019.

COSERIU, E. (1957[19883]): Sincronía, diacronía e historia. El problema del cambio lingüístico. Madrid: Gredos.

CoSERIU, E. (1969[1975²]): Die Geschichte der Sprachphilosophie von der Antike bis zur Ge-genwart. Eine Übersicht. Teil II: Von Leibniz bis Rousseau. (Autorisierte Nachschrift von Gunter Narr). Tübingen: Gunter Narr.

CoseriU, E. (1978): Los universales lingüísticos y los otros. Versión española de C. Parodi. México: Instituto de Investigaciones Filológicas/Centro de Lingüística Hispánica (Cuadernos de Lingüística 2, ALFAL) [en línea] <www.coseriu.de> [14/05/2020]. 
Coseriu, E. (1981): “Creatividad y ténica lingüística. Los tres niveles del lenguaje”, in E. Coseriu: Lecciones de lingüística general. Madrid: Gredos, pp. 269-286.

CoSERIU, E. (1988[1992]): Sprachkompetenz. Grundzüge der Theorie des Sprechens. Tübingen: Francke. Hay versión española: Competencia lingüística. Elementos de la teoría del hablar (elaborado y editado por H. Weber, versión española de F. Meno Blanco). Madrid: Gredos, 1992.

CoseriU, E. (2007): Lingüística del texto. Introducción a la hermenéutica del sentido (edición, anotación y estudio previo de Ó. Loureda Lamas). Madrid: Arco/Libros.

CoSERIU, E. (2019): Competencia lingüística y criterios de corrección. Ed. de A. Matus Olivier y J. L. Samaniego Aldazábal. Sevilla: Editorial Universidad de Sevilla.

Del Rey Quesada, S. (en prensa a): "Discourse Traditions at the intersection of Romance and Latin in the Early Modern Period: Poetry, Dialogue, Doctrinal Prose, and Translation”, in Á. Octavio de Toledo y Huerta y E. Winter Froemel (eds.): Manual of Discourse Traditions in Romance. Berlín: De Gruyter.

DEL REY QUESADA, S. (en prensa b): “Entre género y tradición discursiva: la estructura de la conversación en el diálogo teatral del Siglo de Oro y de la Edad Moderna”, in E. Bustos Gisbert y S Iglesias Recuero (eds.): Pragmática histórica del español: tratamientos, actos de habla y tradiciones discursivas. Sevilla: Editorial Universidad de Sevilla.

DimTER, M. (1985[1999]): “Sobre la clasificación de textos”, in T. Van Dijk (ed.): Discurso y literatura. Nuevos planteamientos sobre el Análisis de los Géneros Literarios. Madrid: Visor Libros, pp. 255-273. Versión esp. de D. Hernández García del original inglés "On Text Classification”, in T. Van Dijk (ed.): Discourse and Literature. Ámsterdam/Philadephia: John Benjamins, pp. 215-230.

DUFTER, A.; STARK, E. (2002): “La variété des variétés: combien de dimensions pour la description? Quelques réflexions à partir du français”, Romanistisches Jahrbuch 53, pp. 81-102. https://doi.org/10.1515/9783110179590.81

ELVIRA GONZÁLEZ, J. (2012): “Gramaticalización y lexicalización: ¿opuestos, paralelos, convergentes...?”, in E. Montero Cartelle (ed.), vol. 1, pp. 315-325.

ESPEjo MuRIEL, M. ㄹ DEL M.; EsPinOSA ElORZA, R. M.a (2012): “Quiçab, quiçá, quizá”, in E. Montero Cartelle (ed.), vol. 1, pp. 749-760.

FERnÁNDEZ AlCAide, M.; LóPEZ SEREnA, A. (eds.) (2007): Cuatrocientos años de la lengua del Quijote. Estudios de historiografía e historia de la lengua española. Actas del $V$ Congreso Nacional de la Asociacion de Jóvenes Investigadores de Historiografía e Historia de la Lengua Esañola (Sevilla, 31 de marzo, 1 y 2 de abril de 2005). Sevilla: Servicio de Publicaciones de la Universidad de Sevilla [en línea] http://hdl.handle.net/11441/60816 [17/04/2021].

FERNÁNDEZ MARTíN, P. (2012): "Estudio de la construcción ser/estar + participio en diversos textos de tipo jurídico-administrativo de los siglos XVI y XVII”, in E. Montero Cartelle (ed.), vol. I, pp. 791-805.

FERNÁNDEZ PÉREZ, M. (1993): “Sociolingüística y Lingüística”, Lingüística Española Actual XV(2), pp. 149-248.

FERNÁNDEZ PÉREZ, M. (1999): Introducción a la lingüística: dimensiones del lenguaje y vías de estudio. Barcelona: Ariel.

Garachana CAmarero, M. (2015): “Teoría de la gramaticalización. Estado de la cuestión”, in J. Ma García Martín (dir.): Actas del IX Congreso Internacional de Historia de la Lengua Española (Cádiz, 10-12 de septiembre de 2012). Madrid/ Frankfurt: Iberoamericana/Vervuert. vol. 1, pp. 331-359.

Garcés Gómez, M. ㄹ P. (2012): “Estudio diacrónico de los marcadores discursivos para su descripción en un diccionario histórico”, in E. Montero Cartelle (ed.), vol. II, pp. 2689- 2701. 
Gimeno MenÉndeZ, F. (1995): Sociolingüística histórica (siglos X-XIII). Madrid: Visor Libros/Universidad de Alicante.

GUZMÁn RIVERón, M. (2007): “Tradiciones discursivas e historia de la lengua española en América”, in M. Fernández Alcaide y A. López Serena (eds.), pp. 79-87.

Haiman, J. (1994): “Ritualization and the development of language”, William Pagliuca (ed.): Perspectives on Grammatization, Ámsterdam/Filadelfia: John Benjamins, pp. 3-28.

HALLIDAY, M. A.K.; HASAN, R. (1985): Language, context, and text: aspects of language in a social-semiotic perspective. Oxford: Oxford University Press.

Hoyos Hoyos, C. (2012): “El Scholastico de Cristóbal de Villalón en el siglo XXI”, in E. Montero Cartelle (ed.), vol. II, pp. 2239-2250.

JACOB, D.; KABATEK, J. (eds.) (2001): Lengua medieval y tradiciones discursivas en la Península Ibérica. Descripción gramatical - pragmática histórica - metodología. Madrid/Frankfurt: Iberoamericana/Vervuert.

КАВАТЕК, J. (2000): “L'oral et l'écrit - quelques aspects théoriques d'un 'nouveau' paradigme dans le canon de la linguistique romane”, in W. Dahmen, G. Holtus, J. Kramer, M. Metzeltin, W. Schweickard, 0. Winkelmann (eds.): Kanonbildung in der Romanistik und in den Nachbardisziplinen. Romanistisches Kolloquium XIV, Tübingen: Narr, pp. 305-320.

KAвATEK, J. (2001): “Cómo investigar las tradiciones discursivas medievales? El ejemplo de los textos jurídicos castellanos”, in D. Jacob y J. Kabatek (eds.), pp. 97-132.

KABATEK, J. (2005a[2018]): “Tradiciones discursivas y cambio lingüístico”, Lexis 29, pp. 151-177. Recogido en J. Kabatek, 2018, pp. 163-183 [en <http://revistas.pucp.edu.pe/index.php/lexis/article/view/8387> [17/04/2021].

KABATEK, J. (2005b): “Sobre a historicidade de textos”, traduçāo de José da Silva Simões, Linha d'água 17, pp. 159-170. https://doi.org/10.11606/issn.2236-4242.v0i17p157-170

KABATEK, J. (2008): “Introducción”, in J. Kabatek (ed.), pp. 7-16.

KABATEK, J. (2011[2018]): “Diskurstraditionen und Genres”, in S. Dessì-Schmid, U. Detges, P. Gévaudan, W. Mihatsch y R. Waltereit, Richard (eds.): Rahmen des Sprechens. Beiträge zu Valenztheorie, Varietätenlinguistik, Kreolistik, Kognitiver und Historischer Semantik. Peter Koch zum 60. Geburtstag. Tübingen: Narr, pp. 89-100. Hay versión española: “Tradición discursiva y género”, in J. Kabatek, 2018, pp. 199-208.

KABATEK, J. (2012[2018]): “Nuevos rumbos en la sintaxis histórica del español”, in E. Montero Cartelle (ed.), vol. I, pp. 77-100. Recogido en J. Kabatek, 2018, pp. 123-143.

KABATEK, J. (2015a): "Warum die 'zweite Historizität' eben doch die zweite ist - von der Bedeutung von Diskurstraditionen für die Sprachbetrachtung”, in F. Lebsanft y A. Schrott (eds.): Diskurse, Texte, Traditionen: Modelle und Fachkulturen in der Diskussion. Göttingen: V\&R Unipress, pp. 49-62.

КАВАТЕК, J. (2015[2018]): “Sobre usos y abusos de la terminología lingüística”, Revue de linguistique romane (RliR) 79, pp. 331-359. https://doi.org/10.31819/9783954877508-006. Recogido en J. Kabatek, 2018, pp. 81-105.

KАВАТЕК, J. (2018): Lingüística coseriana, lingüística histórica, tradiciones discursivas. Ed. de C. Bleorţu y D. P. Gerards. Madrid/Frankfurt: Iberoamericana/Vervuert. 
KAвATEK, J. (2020): “Linguistic Norm in the Linguistic Theory of Eugenio Coseriu”, in F. Lebsanft y F. Tacke (eds.): Manual of Standardization in the Romance Languages. Berlín/Nueva York: De Gruyter, pp. 127144. https://doi.org/10.1515/9783110458084-004

KABATEK, J. (2021): "Eugenio Coseriu on immediacy, distance and discourse traditions", in C. Munteanu y K. Willems (eds.): Eugenio Coseriu. Past, Present and Future. Berlín: Mouton De Gruyter, en prensa.

KABATEK, J. (ed.) (2008): Sintaxis histórica del español y cambio lingüístico: Nuevas perspectivas desde las Tradiciones Discursivas. Madrid/Frankfurt: Iberoamericana/Vervuert.

KLOSS, H. (1978²): Die Entwiclung neuer germanischer Kultursprachen seit 1800. Düsseldorf: Schwann.

Koch, P. (1987): Distanz im Dictamen. Zur Schriftlichkeit und Pragmatik mittelalterlicher Brief- und Redemodelle in Italien. Friburgo. Tesis de habilitación inédita.

Koch, P. (1988): “Norm und Sprache”, in J. Albrecht, J. Lüdkte y H. Thun (eds.): Energeia und Ergon. Studia in Honorem Edugenio Coseriu. Tübingen: Narr, vol. 2, pp. 327-354.

Косн, P. (1997): “Diskurstraditionen: zu ihrem sprachtheoretischen Status und ihrer Dynamik", in B. Frank, Th. Haye y D. Tophinke (eds.): Gattungen mittelalterlicher Schriftlichkeit. Tübingen: Narr, pp. 43-79.

KосH, P. (2008): “Tradiciones discursivas y cambio lingüístico: el ejemplo del tratamiento vuestra merced en español”, in J. Kabatek (ed.), pp. 53-87.

Koch, P. Y W. Oesterreicher (1985): "Sprache der Nähe / Sprache der Distanz. Mündlichkeit und Schriftlichkeit im Spannungsfeld von Sprachtheorie und Sprachgeschichte", Romanistisches Jahrbuch 36, pp. 15-43. https://doi.org/10.1515/9783110244922.15

KOCH, P. Y W. OESTERREICHER (1990[2007]): Lengua hablada en la Romania: español, francés, italiano. Madrid: Gredos. Versión española de A. López Serena a patir del original alemán de 1990: Gesprochene Sprache in der Romania: Französisch, Italienisch, Spanisch. Tübingen: Niemeyer.

KoCH, P. y W. OESTERREICHER (2011): Gesprochene Sprache in der Romania: Französisch, Italienisch, Spanisch. Berlín: De Gruyter.

LEBSANFT, F. (2005): “Kommunikationsprinzipien, Texttraditionen, Geschichte”, in A. Schrott y H. Volker (eds.): Historische Pragmatik und historische Varietätenlinguistik in den romanischen Sprachen. Göttingen: Universitätsverlag Göttingen, pp. 25-43.

LEBSANFT, F. (2006): “Sprecher zwischen Tradition und Innovation: Zum Problem von 'Diskurstraditionen' und 'Diskursgemeinschaften' am Beispiel der Sprache der Politik", Zeitschrift für romanische Philologie 122, pp. 531-548. https://doi.org/10.1515/ZRPH.2006.531

LÓPEZ SERENA, A. (2006): "La edición como construcción del objeto de estudio. El ejemplo de los corpus orales", in L. Pons Rodríguez (ed.): Historia de la lengua y crítica textual. Madrid/Frankfurt: Iberoameicana/Vervuert, pp. 303-336.

LÓPEZ SERENA, A. (2007): "Las tradiciones discursivas en la historiografía lingüística y en la historia de la lengua española", in M. Fernández Alcaide y A. López Serena (eds.), pp. 49-54. [en línea] http://hdl.handle.net/11441/60816 [17/04/2021].

LÓPEZ SERENA, A. (2011): "La doble determinación del nivel histórico en el saber expresivo. Hacia una nueva delimitación del concepto de tradición discursiva", Romanistisches Jahrbuch 62, pp. 59-97. https://doi.org/10.1515/roma.62.3

LÓPEZ SERENA, A. (2012): “Lo universal y lo histórico en el saber expresivo: variación situacional vs. variación discursiva”, Analecta Malacitana LXXXVI(2), pp. 261-281. [en línea] http://hdl.handle.net/11441/39461 [17/04/2021]. 
LÓPEZ SERENA, A. (2013): “Variación y variedades lingüísticas: un modelo teórico dinámico para abordar el estatus de los fenómenos del español hablado en Andalucía”, in A. Narbona Jiménez (coord.): Conciencia y valoración del habla andaluza. Sevilla: Universidad Internacional de Andalucía, pp. 73-127. [en línea] https://dspace.unia.es/bitstream/handle/10334/3976/2013 habla andaluza.pdf [17/04/2021].

LóPEZ SEREnA, A. (2015): “La tensión entre teoría y norma en la Nueva gramática de la lengua española. Una falsa disyuntiva epistemológica”, BRAE tomo XCV, cuaderno CCCXI, pp. 143-166. [en línea] http://revistas.rae.es/brae/article/view/43 [17/04/2021].

LÓPEZ SERENA, A. (2019a): La lingüística como ciencia humana. Una incursión desde la filosofía de la ciencia. Madrid: Arco/Libros.

LóPEz SERENA, A. (2019b): “La interrelación entre Lingüística y Filosofía en Sincronía, diacronía e historia de Eugenio Coseriu”, Onomázein 45, pp. 1-30 http://dx.doi.org/10.7764/onomazein.45.10

López Serena, A. (en prensa a): “Discourse Traditions and Linguistic Variation”, in E. Winter-Froemel y Á. Octavio de Toledo y Huerta (eds.): Manual of Discourse Traditions in Romance. Berlín: De Gruyter.

LóPEz SEREnA, A. (en prensa b): "Algunas cuestiones pendientes en el modelo distancia vs. inmediatez. Los parámetros situacionales que determinan las formas de la variación concepcional”, in T. Gruber et al. (eds.): Was bleibt von Nähe und Distanz? Mediale und konzeptionalle Aspekte von Diskurstraditionen und sprachlichem Wandel. Tübingen: Gunter Narr.

LóPEz SEREnA, A. (en preparación): "Las tradiciones discursivas y la distinción coseriana entre el nivel individual y el nivel histórico del lenguaje".

LouredA, Ó. (2005): “El texto según Eugenio Coseriu”, in J. G. Martínez del Castillo (ed.): Eugenio Coseriu in memoriam. Granada: Granada Lingvistica, pp. 101-122.

LouredA, Ó. (2008): “Zur Frage der Historizität von Texten”, Romanistisches Jahrbuch 58, pp. 29-40. https://doi.org/10.1515/9783110206661.1.29

Lukin, A; Moore, A. R.; Herke, M.; Wegener, R.; Wu, C.E (2011): “Halliday's model of register revisited and explored", Linguistcs and the Human Sciences 4(2), pp. 187-213.

MARTí SÁnCHEZ, M. (1998): En torno a la cientificidad de la Lingüística: Aspectos diacrónicos y sincrónicos. Alcalá de Henares: Servicio de Publicaciones de la Universidad de Alcalá.

MÉNDEZ García DE PAREDes, E. (1999): “La norma idiomática del español: visión histórica”, Philologia Hispalensis 13, pp. 109-132. http://dx.doi.org/10.12795/PH.1999.v13.i01.08

Montero Cartelle, E. (ed.) (2012): Actas del VIII Congreso Internacional de Historia de la Lengua Española (Santiago de Compostela, 14-18 de septiembre de 2009). Madrid: Meubook.

NARBona JimÉnEZ, A. (2009): "Reseña de Johannes Kabatek (ed.), Sintaxis histórica del español y cambio lingüístico: Nuevas perspectivas desde las Tradiciones Discursivas (Lingüística Iberoamericana, vol. 31), Iberoamericana/Vervuert, Madrid/Frankfurt am Main, 2008", Revista de Historia de la Lengua Española 4, pp. 79-87.

OCTAVIO DE Toledo y HuERTA, Á. (2018): “Tradiciones discursivas o tradicionalidad? ¿Gramaticalización o sintactización? Difusión y declive de las construcciones modales con infinitivo antepuesto”, in J. L. Girón Alconchel, F. J. Herrero Ruiz de Loizaga, D. M. Sáez Rivera (eds.): Procesos de textualización y gramaticalización en la historia del español, Madrid: Iberoamericana, pp. 79-134.

Oesterreicher, W. (1997): “Zur Fundierung von Diskurstraditionen”, in B. Frank, Th. Haye y D. Tophinke (eds.): Gattungen mittelalterlicher Schriftlichkeit. Tübingen: Narr, pp. 19-41. 
OEsterreicher, W. (2001a): "Historizität - Sprachvariation, Sprachverschiedenheit, Sprachwandel”, in M. Haspelmath, E. König, W. Oesterreicher y W. Raible (eds.): Language Typology and Language Universals/Sprachtypologie und sprachliche Universalien/La typologie des langues et les universaux linguistiques. Berlín/Nueva Yorl: De Gruyter, vol. 2, pp. 1554-1595.

OESTERREICHER, W. (2001b): "Sprachwandel, Varietätenwandel, Sprachgeschichte. Zu einem verdrängten Teoriezusammenhang", in U. Schaefer y E. Spielmann (eds.): Varieties and Consequences of Literacy and Orality/Formen und Folgen von Schriftlichkeit und Mündlichkeit. Franz H. Bäuml zum 75. Geburtstag. Tübingen: Narr, pp. 217-248.

OESTERREICHER, W. (2002): "Sprachwandel - Corpusbefunde, Sprachregeln, kognitive Konstanten", Romanistisches Jahrbuch 53, pp. 31-55. https://doi.org/10.1515/9783110179590.31

OESTERREICHER, W. (2004): “Textos entre inmediatez y distancia comunicativas. El problema de lo hablado en lo escrito en el Siglo de Oro", in R. Cano (ed.): Historia de la lengua española. Barcelona: Ariel, pp. 729769.

OESTERREICHER, W. (2006): “La historicidad del lenguaje: variación, diversidad y cambio lingüístico", in J. J. de Bustos Tovar y J. L. Girón Alconchel (eds.): Actas del VI Congreso Internacional de Historia de la Lengua Española. Madrid: Arco/Libros, vol. 1, pp. 137-158.

OESTERREICHER, W. (2008): “Dinámicas de estructuras actanciales en el Siglo de Oro: el ejemplo del verbo encabalgar", in J. Kabatek (ed.), pp. 225-248.

OESTERREICHER, W. (2012): “Innovación y cambio gramatical: formulaciones ad hoc, difusión de innovaciones y formas del cambio lingüístico”, in E. Montero Cartelle (ed.), vol. I, pp. 228-246.

Pons RodRíGUEZ, L. (2008): "El peso de la tradición discursiva en un proceso de textualización: un ejemplo en la Edad Media castellana”, in J. Kabatek (ed.), pp. 197-224.

Porcar Miralles, M. (2012): "La construcción del discurso científico: A propósito de las operaciones discursivas", in E. Montero Cartelle (ed.), vol. 1, pp. 247-261.

Rivarola, J. L. (2012): "Los corpora en el estudio histórico del español de América (un corpus documental del español en el Perú de los siglos XVI y XVII): reflexiones perspectivas”, in E. Montero Cartelle (ed.), vol. I, pp. 391-396.

SÁEz RiverA, D. M. (2007): “Tradiciones discursivas, historiografía lingüística e historia de la lengua”, in M. Fernández Alcaide y A. López Serena (eds.), pp. 89-103. [en línea] http://hdl.handle.net/11441/60816 [17/04/2021].

SÁEz RiverA, D. M. (2018): “Una propuesta de aplicación de la teoría de las tradiciones discursivas: alrededor de las relaciones de autos de fe", in X. A. Álvarez, J. J. García, M. Martí y A. M. Ruiz (eds.): Nuevas perspectivas en la diacronía de las lenguas de especialidad. Alcalá de Henares: Servicio de Publicaciones de la Universidad de Alcalá, pp. 411-428.

SCHLIEBEN-LANGE, B. (1983): Traditionen des Sprechens: Elemente einer pragmatischen Sprachgeschichtsschreibung. Stuttgart: W. Kohlhammer.

Schlieben-LAnGE, B. (1990): “Normen des Sprechens, der Sprache und der Texte”, in W. Bahner, J. Schildt y D. Viehweger (eds.): Proceedings of the Fourteenth International Congress of Linguistics. Berlín: Akademie Verlag, vol. I, pp. 114-124.

SCHLIEBEn-LANGE, B; WEYDT, H. [con contribuciones de E. Coseriu y H.-U. Gumbrecht] (1979): “Streitgespräch zur Historizität von Sprechakten", Linguistische Berichte 60, pp. 65-78.

SöLL, L. (1985³): Gesprochenes und geschriebenes Französisch. Berlín: Schmidt. 
Steger, H.; Deutrich, K-H.; SChanK, G.; SchÜTZ, E. (1974): “Redekonstellation, Redekonstellationstyp, Textexemplar, Textsorte im Rahmen eines Sprachverhaltensmodells. Begründung einer Forschungshypothese”, in H. Moser (ed.): Gesprochene Sprache. Jahrbuch 1972 des Instituts für duetsche Sprache. Düsseldorf: Schwann, pp. 39-97.

WiLhElm, R. (2001): “Diskurstraditionen”, in M. Haspelmath et al. (eds.): Sprachtypologie und sprachliche Universalien. Berlín: De Gruyter, pp. 466-477.

WiLhelm, R. (2015), "Diskurstraditionen und einzelsprachliche Traditionen”, in F. Lebsanft y A. Schrott (eds.): Diskurse, Texten, Traditionen: Modelle und Fachkulturen in der Diskusssion. Bonn: Bonn University Press / Vandenhoeck \& Ruprecht, pp. 63-78.

Winter-Froemel, E.; López Serena, A; Octavio de Toledo y Huerta, Á. S.; Frank-Job, B. (eds.) (2015): Diskurstraditionelles und Einzelsprachliches im Sprachwandel / Tradicionalidad discursiva $e$ idiomaticidad en los procesos de cambio lingüístico. Tübingen: Gunter Narr.

Zamorano AGUilar, A. (2020): “Tradiciones discursivas (TD) y series textuales (ST): convergencias y divergencias teóricas”, in A. López Serena, S. Del Rey Quesada y E. Carmona Yanes (eds.): Tradiciones discursivas y tradiciones idiomáticas en la historia del español moderno. Berlín: Peter Lang, pp. 485-509.

\section{Notas}

* Este trabajo es resultado del proyecto I+D "Tradicionalidad discursiva e idiomática, sintaxis del discurso, traducción y cambio lingüístico en la historia del español moderno: prosa (pre-)periodística/ensayística y literaria” (PGC2018-097823-в-I00), financiado por el Ministerio de Ciencia, Innovación y Universidades del Gobierno de España (convocatoria 2018 de proyectos de I+D de "Generación de conocimiento", Programa Estatal de Generación de Conocimiento y Fortalecimiento Científico y Tecnológico del Sistema de I+D, Plan Estatal de Investigación Científica y Técnica y de Innovación 2017-2020), con participación de fondos FEDER. La idea de redactarlo surgió a raíz de la invitación, por parte de Esme Winter-Froemel y Álvaro Octavio de Toledo y Huerta, para participar, con un capítulo titulado "Discourse Traditions and Variation Linguistics", en el Manual of Discourse Traditions in Romance coordinado por ellos. En paralelo a la preparación de ese capítulo, que verá la luz en inglés a lo largo de 2021 o 2022 , redacté también estas páginas, directamente en español, cuya versión final se ha visto beneficiada por las pertinentes observaciones de Antonio Narbona Jiménez, Rafael Cano Aguilar, Johannes Kabatek, Santiago del Rey Quesada y los dos revisores anónimos que informaron positivamente sobre su contenido. Paradójicamente, dado que los ritmos de edición de artículos y capítulos de manuales son muy distintos, la publicación de este artículo, que es, en su génesis, corolario de las reflexiones en que se fundamenta ese capítulo de manual, posiblemente se interprete, a la postre, como su germen.

1 Octavio de Toledo (2018: 118) habla, a este respecto, de "lingüística variacional neocoseriana". Aunque tal denominación tiene, frente a "Lingüística de las variedades de filiación coseriana", varias ventajas, entre ellas su menor extensión, su eufonía y una sintaxis sin complementos del nombre preposicionales que dificulten la mnemotecnia, me resisto - al menos de momento- a adoptarla por dos motivos. En primer lugar, porque el adjetivo variacional vela la importante oposición que, dentro de esta corriente, se establece entre los términos variación y variedades (cf. López Serena 2013 e infra, en este mismo epígrafe de introducción). En segundo lugar, porque mientras que la expresión "de filiación coseriana" manifiesta, a mi modo de ver, que el principal valor de las ideas de Coseriu para este enfoque ha sido el de servirles de fundamento, el adjetivo neocoseriano podría generar la falsa impresión de que todas las aportaciones de Koch, Oesterreicher o Kabatek, entre otros, tenían el pensamiento de Coseriu no solo como fundamento, sino también como horizonte de la reflexión, cuando, en realidad, al menos en lo que concierne a Koch y Oesterreicher, el propósito de sus propuestas de teorización lingüística nunca fue desarrollar específicamente la teoría del lenguaje coseriana, sino construir "ein sprachtheoretisch fundiertes Gesamtkonzept von Mündlichkeit und Schriftlichkeit" (Koch y Oesterreicher 2011: x), es decir, "una concepción global de la oralidad y la escrituralidad teóricamente fundamentada" (Koch y Oesterreicher 2007:13), para lo cual se sirvieron tanto de distinciones netamente coserianas, como de conceptos y aproximaciones de muchos otros autores, entre los que cabe destacar a Ludwig Söll (1985³), Hugo Steger et al. (1974) o Heinz Kloss (1978²).

2 Como señalan Bleorțu y Gerards (2018: 11), en la "Nota de los editores" que abre el volumen compilatorio, editado por ellos, de los trabajos reunidos en Kabatek (2018), "el creciente número de estudios especializados en TD [...] no solo ha llevado al efecto positivo de su aceptación cada vez mayor, sino también a una serie e imprecisiones y confusiones”. Cf. también infra nn. 10 y 11.

${ }^{3}$ Sobre la diferenciación entre materia y objeto de estudio, cf. infra, en este mismo epígrafe, así como Fernández Pérez (1993: 213215; 1999: 23). También Gimeno Menéndez (1995: 22) realiza esta distinción. Una diferenciación similar, aunque con otra 
terminología, se encuentra en Bernardo Paniagua (1999). Cf., asimismo, Martí Sánchez (1998, cap. 6) y López Serena (2006: 304; 2019b: 14, n. 2).

4 En el epígrafe 4 del trabajo que este autor dedicó en 2018 a la difusión y el declive de las construcciones modales con infinitivo antepuesto, trabajo cuyo título comenzaba, precisamente, por la pregunta “ ¿Tradiciones discursivas o tradicionalidad?”, Octavio de Toledo señalaba acertadamente que para quienes adoptan lo que en estas páginas se denomina perspectiva de materia, es decir, "[p]ara quienes no necesariamente asumen todos los postulados teóricos de la lingüística variacional neocoseriana en que se inserta la noción de TD [cf. supra n. 1], sino que buscan en estas principalmente un instrumento práctico (antes que conceptual) para el análisis de la trayectoria de un fenómeno lingüístico, la diferencia entre las TD y los géneros amenazaría con verse reducida a un mero conflicto nominal" (Octavio de Toledo 2018: 118).

5 En concreto, la formulación exacta de las palabras de Kabatek, que he tratado de parafrasear sin desvirtuar su espíritu, pero omitiendo la referencia al ejemplo del Libro del conde Lucanor del que él se servía en su argumentación, es la siguiente: "Die ganze Tragweite des Begriffs der Diskurstraditionen [...] scheint mir nur dann überhaupt erfassbar, wenn wir zunächst eine radikale Umkehrung der Perspektive vornehmen. Gehen wir hierfür zum Conde Lucanor zurück und fragen uns nicht nach der Gattungseinordnung des Werks, sondern der Traditionen des Textes. Und beginnen wir dabei nicht mit dem Text als Ganzheit, sondern mit einem einzigen Satz aus einem Exempel" (Kabatek 2015a: 52). A lo que más adelante, aún a propósito del mismo ejemplo, añadía una descripción muy ilustrativa de en qué consiste exactamente lo que en estas páginas se denomina aproximación a las TD desde una perspectiva de materia: "Wenn wir einen Text nicht von der vorhandenen Kategorisierung her betrachten und in die eine oder andere Kategorie einordnen wollen, sondern die ganze Tragweite der Traditionsbezüge im Text vom Text ausgehend bestimmen wollen, so werden wir eine lange, grundsätzlich offene Liste von Traditionellem in einem Text finden" (Kabatek 2015a: 54), formulación que podríamos traducir más o menos así: "Si abordamos un texto no a partir de una categorización preestablecida y sin querer adscribirlo a una u otra categoría, sino pretendiendo determinar el alcance completo de las relaciones de tradicionalidad que se manifiestan en ese texto partiendo del propio texto, encontraremos una larga lista, en principio abierta, de aspectos tradicionales".

${ }^{6}$ Con ayuda de la fonología, se puede comprender muy fácilmente esta distinción, que está también en la base de la oposición que establece Oesterreicher entre datos y hechos lingüísticos (cf. infra, en este mismo epígrafe). Cuando queremos hacer una transcripción de un educto verbal, el educto originario constituye la materia de estudio, puesto que es la realidad fenoménica que nos proporciona los datos. Ahora bien, tras la grabación y posterior transcripción, primero fonética y después fonológica, de dicho educto, el producto de este proceso de abstracción, modelización e interpretación de la realidad fenoménica originaria ya no es, en absoluto, la mera materia fónica de la que partíamos. Su disección lo ha convertido en una construcción indesligable de los conceptos teóricos y de la metodología de segmentación y análisis que se haya puesto en práctica para generar la transcripción en cuestión. Este es el motivo por el que podemos admitir que los sonidos originalmente emitidos son parte de la materia o realidad fenoménica de la realización oral de una lengua, pero debemos asumir que los fonos y fonemas que identificamos en dicha realización oral no existen, en tanto que objetos de estudio, fuera de nuestras teorías fonológicas.

${ }^{7}$ A propósito de la distinción entre teoría lingüística, lingüística general y lingüística histórica, cf. Coseriu (1969[1975²]), así como López Serena (2019a, 2019b).

8 Con respecto con esta distinción, se puede ver también, como ya se ha anticipado supra, López Serena (2013).

${ }^{9}$ A este respecto, es interesante señalar que Kabatek (2018: 22) vincula "el enorme eco que tuvo [su primer] libro [sobre TD (Jacob y Kabatek, eds., 2001)] en el mundo hispánico" con el hecho de que apareció "en un momento adecuado: la teoría de la gramaticalización y los nuevos grandes corpus habían dado un nuevo auge a la lingüística histórica, y en el ámbito de la lingüística hispánica hubo una especie de oleada de estudios de sintaxis histórica. Entre la tradición filológica española y una nueva lingüística de índole más bien teórica y basada en datos masivos faltaba algo: una diferenciación de las tradiciones de los textos y una crítica a una diacronía demasiado simplista que ignoraba la diversidad de las tradiciones textuales". Cf. también infra $\S 3$.

${ }^{10}$ La propuesta de Koch no se cotejará en profundidad, en estas páginas, con posiciones ligeramente divergentes de la suya, como la defendida en algunos trabajos por Johannes Kabatek (2005b, 2015a, 2018, 2021), quien entiende que la historicidad propia de las lenguas es distinta de la historicidad, de segundo orden, que caracteriza a las TD, y apuesta, en consecuencia, por vincular estas últimas más que con el nivel histórico del lenguaje, con el nivel individual del discurso y por considerarlas más próximas a la naturaleza del ergon que de la enérgeia (cf. infra $\S \S 2$ y 3). Kabatek, que presenta - a mi modo de ver sin llegar a justificarlo suficientemente (cf. López Serena, en preparación) - su visión como "la concepción coserianamente 'ortodoxa'” de la tradicionalidad de los textos (Kabatek 2018: 18) sostiene, frente a Koch, que el empleo, por parte de cualquier hablante, del tipo de repetición que da lugar a un vínculo discursivo-tradicional no deriva de un saber técnico propiamente dicho, que es el tipo de competencia que él considera privativo del nivel histórico: "die Phänomene der zweiten Historizität, die Traditionsphänomene, bei denen ein Produkt A' dem Produkt A analog geschaffen wird [beziehen sich] beide [...] nicht qua Technik, sondern qua Produkte, qua individuelle Ereignisse aufeinander" (Kabatek 2015a: 59) [“los fenómenos de la segunda historicidad, los fenómenos tradicionales, en los que un producto A' se construye en analogía con un producto A, no se relacionan entre sí como técnicas, sino como productos, como ocurrencias individuales" (la traducción es mía)].

Para este autor, una importante diferencia entre primera y segunda historicidad es que la primera es ilimitada mientras que la segunda es limitada: "el concepto de TD [...] pone énfasis sobre la tradición de los textos, una tradición separable de la historicidad primaria de los sistemas lingüísticos, a la que se refiere el hablar y que es evocada cuando se habla o escribe. 
Se trata de una especie de "segunda historicidad": frente a la primera (o primaria), interiorizada como técnica libre para la producción de una cantidad ilimitada de enunciados, esta segunda historicidad es limitada, pues se refiere a los textos ya producidos en una comunidad, al acervo cultural, la memoria textual o discursiva” (Kabatek 2008: 9; cf. también Kabatek 2018: 15, 24). También para Koch “[e]s innegable que la 'historicidad' de las tradiciones discursivas es algo diferente de la 'historicidad' de las lenguas históricas: los grupos constitutivos de la[s] tradiciones discursivas son grupos profesionales o religiosos, corrientes literarias, movimientos políticos, etc.; los grupos constitutivos de las lenguas históricas son comunidades lingüísticas (cfr. Schlieben-Lange 1983: 139; 1990: 116; Koch 1997: 49). Hay una diferencia importante entre los dos: las lenguas históricas (o sus variedades) definen a los grupos (es decir las comunidades lingüísticas), mientras que son los grupos (profesionales, religiosos, literarios, etc.) los que definen a las tradiciones discursivas (cfr. Coseriu 1988: 86; también Kabatek 2001: 99s.) Sin embargo, tanto las lenguas históricas como las tradiciones discursivas constituyen tradiciones del hablar (cfr. Schlieben-Lange 1983: 138s.)" (Koch 2008: 55), es decir, forman parte del dominio histórico del lenguaje al que pertenecen las reglas no universales —el dominio histórico-, en tanto en cuanto, a su modo de ver, "no puede haber un tipo de reglas específico en el nivel del discurso, donde los hablantes no hacen sino aplicar reglas elocucionales, idiomáticas y discursivas" (Koch 2008: 55). De hecho, en su opinión, "[s]i dijéramos que el saber discursivo pertenece al nivel del discurso porque se actualiza en este último, tendríamos que aceptar también que el saber idiomático y el saber elocucional pertenecen al nivel del discurso porque ellos también se actualizan en este último" (Koch 2008: 56, n. 5). Cf. también infra, n. 11.

11 Aunque, como ya se ha advertido (cf. supra n. 10), en este trabajo no se va a abordar por extenso la cuestión —que queda pendiente para otro artículo específico (cf. López Serena, en preparación) - de por qué Koch ubica las TD en el nivel histórico del lenguaje mientras que Kabatek prefiere situarlas en el nivel individual, me parece importante dejar al menos apuntada la idea de que, a mi modo de ver, esta disensión está relacionada con el hecho de que Koch concibe la oposición entre el nivel individual y el nivel histórico de la tripartición coseriana en términos epistemológicos, mientras que Kabatek lo hace en términos fenoménicos. Por este motivo, para Koch (1987: 31) (cf. infra § 3) "[a]tribuir al discurso como nivel genuinamente actual del lenguaje [...] un saber reglas [...] [es] una contradicción [...], puesto que las reglas entrañan tipificaciones” (la traducción es mía) y epistemológica mente suponen generalizaciones ubicadas, necesariamente, en un nivel de abstracción superior al de las ocurrencias individuales, mientras que para Kabatek, que aborda la cuestión no desde el contraste epistemológico entre ocurrencias individuales y generalizaciones históricas, sino desde una perspectiva fenoménica, centrada en cómo se relacionan los hablantes con las TD, el tipo de competencia al que se recurre cuando se construye un producto A' en analogía con un producto anterior A no es un saber de carácter técnico, similar al que se pone en práctica en relación con la primera historicidad, sino un saber sobre productos (cf. la cita de Kabatek 2015a: 59 que se reprodujo en la n. 10 supra). Que la distinción entre lo individual "como 'acto lingüístico [...] de un individuo determinado en una situación determinada' (Coseriu 1981: 292)” (Koch 2008: 53; la cursiva es mía) y lo histórico como saber - “[n]o hay que confundir de ningún modo la efectuación actual con el saber virtual que esta 'actualiza'” (Koch 2008: 56) es de cariz epistemológico en Koch y análoga, en cierto modo, a la oposición que se establece en estas páginas entre materia y objeto de estudio, así como entre variación y variedades, lo corrobora el hecho de que, para este autor, la tripartición coseriana del lenguaje que representa la figura 1 “conlleva un problema de lógica: ¿Qué quiere decir 'saber expresivo'? Si tomamos a rajatabla la definición

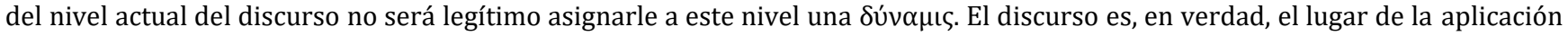
del saber lingüístico, pero como cada discurso es único y el saber implica la posibilidad de la reproducción, saber y discurso serán incompatibles" (Koch 2008: 54; la cursiva es mía). Aparte de enfrentarse a esta oposición desde el punto de vista de la lógica, que es uno de los que importa a la epistemología, Koch también explicita que su enfoque es filosófico cuando se opone a la propuesta de Lebsanft $(2005,2006)$ en los siguiente términos: "no es aceptable asignar el saber expresivo (es decir, el saber "discursivotradicional") al nivel del discurso individual, como lo propone Lebsanft (2005: 31s.; 2006: 536), tratando de salvar el esquema originario [fig. 1]. Hay que respetar que desde el punto de vista filosófico lo universal de los esquemas 1 y 2 corresponde a lo 'general', lo histórico a lo 'particular' y lo actual a lo 'individual' [omito nota]. Basta recordar la definición arriba citada del discurso como 'acto lingüístico [...] de un individuo determinado en una situación determinada'” (Koch 2008: 55; la cursiva es mía). Por último, es importante mencionar que esta oposición filosófica de Koch entre el nivel actual del discurso y el nivel histórico de las regularidades que interesan a la lingüística es afín a la distinción sistemáticamente mantenida por Oesterreicher entre datos y hechos lingüísticos (cf. supra § 1), quien sitúa en el nivel individual de los datos el inicio epistemológico de la investigación, cuyo horizonte no es, empero, el de los datos, sino el de los hechos filtrados por la teoría: “Comenzaremos, pues, por el nivel actual de la observación de lo lingüístico; [...] tendremos que interpretar y clasificar [...] en los textos para transformar los DATOS en HECHOS lingüísticos pertenecientes al nivel del análisis y la descripción idiomático; este segundo nivel es, pues, el que contiene las reglas y normas de las técnicas históricas del hablar" (Oesterreicher 2008: 225; la cursiva y la versalita son mías).

12 Sobre el concepto de norma coseriano, cf. Méndez García de Paredes (1999), Koch (1988), López Serena (2015), Kabatek (2020). 13 Que Dimter (1985[1999]: 260), para diferenciarlas de las funciones idiomáticas, denomina "convencionalismo[s] de textualización".

14 Cf. también Coseriu (1988[1992]), Loureda (2005, 2008), Kabatek (2011[2018]).

15 El original alemán, que se reproduce, tanto en este caso como en los sucesivos, debido a que procede de un documento inédito, reza: "Sie verweisen auf Diskurstraditionen, nämlich auf bestimmte Stile, Gattungen, Textsorten, Diskursuniversen, Sprechakte usw., die jeweils Klassen von Diskursen zusammenfassen” (resalte original). 
${ }^{16}$ Sobre la forma en que la aparición de estos fenómenos en situaciones en las que no constituyen la expectativa de comportamiento marca a los hablantes, cf. infra en $§ 5$ lo que se dice a propósito del modelo de la cadena de variedades, que se reproduce como figura 8 en dicho epígrafe.

17 En esta misma línea, es oportuno traer a colación las siguientes palabras de Lola Pons, que, aunque referidas en su caso específicamente a los textos medievales, resultan metodológicamente extrapolables a la lingüística histórica en general: "los textos medievales se acogen a tipos discursivos que mediatizan fuertemente la formalización de los contenidos en función de una serie de ingredientes implícitos en las rutinas textuales anteriores o explícitos en materiales metatextuales de naturaleza más o menos preceptiva" (Pons Rodríguez 2008: 197). Esto obliga a "entender los textos como híbridos en que convergen y se agregan prácticas discursivas previas" (Pons Rodríguez 2008: 197-198) y conduce a la siguiente constatación: "De nada nos sirve una clasificación histórica de los textos medievales castellanos que los descomponga en categorías herméticas o discretas; tampoco nos valen concepciones de los discursos como constructos monotípicos: si queremos dar cuenta de la relación de la textualidad medieval con el código que le da cuerpo, habremos de buscar una teoría de la clasificación textual que considere los rasgos lingüísticos y su relación con las condiciones de enunciación, que contemple los discursos como objetos sociohistóricos en los que se puede seguir la relación entre los cambios en la historia social y los cambios en los tipos de discursos" (Pons Rodríguez 2008: 221). Cf. también Pons Rodríguez (2008: 198-199).

18 Para Octavio de Toledo, la distinción entre repeticiones semiconscientes y repeticiones conscientes está en la base de la diferenciación establecida por Kabatek (2015a) entre primera y segunda historicidad; de ahí que en la nota a pie de página con que se cierra la cita que se acaba de reproducir afirme: "De hecho, estas reglas y principios (que, en un modelo neocoseriano, son también de naturaleza histórica, por cuanto propias de una lengua concreta y potencialmente ceñidas a un tiempo limitado) formarían parte de una primera historicidad en la que el hablante se halla inmerso desde su nacimiento y de la que participa semiconscientemente, mientras que los fenómenos culturales dotados de función simbólica en una sociedad determinada se desenvuelven en el ámbito de una segunda historicidad (Kabatek 2015a) a la que, como es fácil colegir, se adscriben las TD" (Octavio de Toledo 2018: 120, n. 39; cursiva original). Sobre la diferencia entre la primera y la segunda historicidad, cf. también supra n. 10. 19 El texto original alemán de esta cita es: "einerseits die linguistische Analyse der Gattung dictamen anhand typischer Texte, die lateinisch und - erstmals - im volgare abfefasst sind; andererseits die linguistische Analyse des erstmaligen Einsatzes del volgare innerhalb der Gattung dictamen".

20 El texto original alemán de esta cita es: "über einen sprachtheoretischen kategorialen Rahmen, innerhalb dessen sich die verschiedenen Fragestellungen bei der Behandlung der dictamina exakt situieren, abgrenzen und verknüpfen lassen".

21 Recuérdese, a este respecto, una de las citas de Octavio de Toledo (2018) que se ha reproducido más arriba: "Una definición basada en la idea de repetición evocadora y ampliable a elementos o secuencias inferiores al texto e incluso a la oración convierte a las TD, como es fácil de entender, en entidades extraordinariamente atractivas para quien investiga la historia de la lengua, por cuanto le proporcionan una herramienta previamente inexistente para conectar directamente la repetición de un elemento o construcción (su frecuencia, en suma) con una distribución restringida (o, al menos, dominante) en un conjunto de textos interrelacionables según criterios varios (pero no necesariamente dependientes unos de otros, ni en términos genéricos ni de rasgos de género: una constelación textual [el término es de Kabatek (2015a)])" (Octavio de Toledo 2018: 119; cursiva original).

22 El texto original alemán de esta cita es: "Was [...] das expressive Wissen betrifft, so ist es weder aktuell noch auch individuell. [...] Insofern als es sich hier um ein durch und durch historisch geprägtes Wissen handelt, gehört das expressive Wissen auf dieselbe Ebene wie das idiomatische Wissen".

${ }^{23}$ Reproduzco el original alemán: "Das expressive Wissen gehört also nicht zur Ebene des Diskurses, sondern zur historischen Ebene in den Bereich der Diskurstraditionen, die aber eben direkter als die Einzelsprachen auf die Ebene des Diskurses zugeschnitten sind".

24 "Dem Diskurs als genuin aktueller Ebene des Sprachlichen eine $\delta u ́ v \alpha \mu \varsigma$, also ein Wissen von Regeln zuzuordnen, wäre ein Widerspruch in sich, da Regeln Typisierungen beinhalten und nicht einmalig angewandt werden können". Cf. también supra n. 11. 25 “Nach Wittgenstein 'kann nicht ein einziges Mal nur ein Mensch einer Regel gefolgt sein'” (1967, § 199)”.

26 Cf. también Loureda (2008).

27 Que se trata de saberes en cierta manera autónomos se puede comprobar también en el hecho de que, en ocasiones, las normas idiomáticas contravienen los principios generales del pensar propios del saber elocutivo (por ejemplo cuando se convencionalizan expresiones que infringen el principio de no redundancia, como "ver algo con nuestros propios ojos" o "subir para arriba") y, asimismo, también es posible que las normas propias del saber discursivo contravengan las normas idiomáticas, o, dicho de otro modo, "las reglas del nivel de las lenguas pueden quedar en suspenso en el texto, es decir, pueden dejar de aplicarse por la configuración tradicional del texto o por alguna motivación que se encuentra en el texto mismo" (Coseriu 2007: 133) (como ocurre cuando, por ejemplo, voluntariamente, se omiten determinadas palabras funcionales en un telegrama); cf. Coseriu (2007: 133 -136 y 2019) para otros ejemplos.

${ }^{28}$ Caracterizadas por presentar valores opuestos en relación con criterios como el carácter público o privado de la comunicación, la confianza o falta de confianza entre los interlocutores, la presencia o ausencia de emocionalidad, el anclaje o falta de anclaje en la situación y la acción comunicativas, la posible o imposible referencialización desde el aquí y ahora del hablante, la proximidad o distancia física, la posibilidad o imposibilidad de cooperación, el carácter dialógico o monológico del discurso, la espontaneidad o 
planificación previa, la libertad o fijación temática. Sobre la modificación que los parámetros que delimitan la inmediatez y la distancia comunicativa experimentaron entre la propuesta originaria de Koch y Oesterreicher de 1985 y la de 1990[2007], cf. López Serena (en prensa b).

${ }^{29}$ Asimismo es necesario tener en cuenta lo que Bajtín denominaba reacentuación de los géneros o empleo de determinados géneros en situaciones comunicativas que no son las prototípicamente asociadas a ellos.

30 Con respecto a esta expresión, cf. también Oesterreicher (2008: 241) y Del Rey Quesada (en prensa a).

31 Hago abstracción, en este contexto, de la propuesta formulada en López Serena (2011) de concebir las TD como subdeterminaciones históricas de los textos, que ha servido a Del Rey Quesada (en prensa b) para distinguir entre marcas discursivo-genéricas y marcas discursivo-tradicionales.

${ }^{32}$ No tenemos en cuenta, en esta distinción, el hecho, para algunos controvertido (cf. Kabatek 2000, Dufter y Stark 2002), de que Koch y Oesterreicher postularan también una variación concepcional de carácter histórico, a la que corresponde, en la figura 8, el nivel 1b. En todo caso, tanto su consideración como su inclusión en la figura 10 serían muy sencillas: bastaría con subdividir en dos las celdas correspondientes a la variación situacional de carácter histórico, de manera que esta aprehendiera tanto la variación concepcional de carácter histórico como la variación diafásica.

$33 \mathrm{Al}$ formular esta correlación entre teorización y variedades, por un lado, y descripción y variación, por otro, soy consciente de estar incurriendo en una simplificación, toda vez que también la descripción recurre a categorías teóricas y se practica, como hemos visto que señalaba Oesterreicher (cf. supra § 3), sobre hechos lingüísticos y no realmente sobre datos crudos.

34 No extraña, pues, que Octavio de Toledo (2012: 118) haya llegado a afirmar, en este sentido (cf. supra § 0, n. 4), que “[p]ara quienes no necesariamente asumen todos los postulados teóricos de la lingüística variacional neocoseriana en que se inserta la noción de TD, sino que buscan en estas principalmente un instrumento práctico (antes que conceptual) para el análisis de la trayectoria de un fenómeno lingüístico, la diferencia entre las TD y los géneros amena[ce] con verse reducida a un mero conflicto nominal" (la cursiva es mía).

35 Como señala acertadamente uno de los revisores anónimos del manuscrito original de este trabajo que se sometió a evaluación por pares ciegos para su publicación en esta revista, es muy posible que en muchos de casos se haya producido incluso una desterminologización. Cf. también, a este respecto, Sáez Rivera (2018).

36 El contexto completo de esta cita es el siguiente: "pretendemos revisar las diferentes hipótesis planteadas sobre el origen de quizá y presentar una nueva. La cuestión de las variantes gráficas y su distribución hasta el siglo xv nos introduce en el mundo de los originales y las copias en el ámbito de los romanceamientos bíblicos, la literatura sapiencial y las traducciones relacionadas con el árabe y el hebreo, obras en las que no debemos olvidar el influjo de las tradiciones discursivas" (Espejo Muriel y Espinosa Elorza 2012: 749).

37 Cf. también Kabatek (2008: 8), que se refiere a que "algo tan evidente difícilmente podría haberse ignorado en el pasado", así como Kabatek (2008: 7): "Con la reciente introducción del paradigma de las Tradiciones Discursivas (TD) en la lingüística contemporánea, parece, a primera vista, que se está poniendo énfasis sobre un hecho absolutamente obvio: se subraya que los textos tienen historia y que esa historia tiene relevancia a la hora de hablar o de escribir, por lo que hay que tener en cue nta esas 'Tradiciones Discursivas' en la descripción lingüística, inclusive la descripción gramatical”.

38 Algo que A. Narbona no considera óbice para que este paradigma haya dado excelentes frutos cuando señala, en su reseña de Kabatek (ed.) (2008), que con este libro "[s]e demuestra una vez más que, en lingüística histórica, no disponer en todos los casos de una clara y convincente definición de un concepto no impide que resulte explicativamente fecundo" (Narbona Jiménez 2009: 87).

39 Esto tiene que ver, naturalmente, con lo que Kabatek (2008: 8-9) denomina "la hipótesis fuerte de la teoría de las Tradiciones Discursivas: que la historia de una lengua no presenta solo variación a nivel de dialectos, sociolectos o estilos sino que la lengua varía también de acuerdo con las tradiciones de los textos, es decir, que estos no sólo añaden sus elementos formales, sus características de género o las marcas de un tipo determinado de estructuración a los productos de sistemas ya dados sino que condicionan o pueden condicionar, a su vez, la selección de elementos procedentes de diferentes sistemas (o de un sistema de sistemas)". Por este motivo, Oesterreicher sostiene que "[n]o son aceptables [...] ciertas opciones en el campo de la llamada teoría de la gramaticalización que prefieren abordar el cambio basándose en información dada y siguiendo modelos unidireccionales del cambio sin anclaje en una documentación textual representativa de un vasto dominio discursivo (cfr. Oesterreicher 2006: 146-153; también 2001a: 1576-1582 y 2001b: 236s.). Estas orientaciones no analizan previamente lo que fundamenta la investigación lingüística seria, es decir la documentación discursiva con sus riquezas variacionales y pragmáticas (cfr. Oesterreicher 2002 y 2004)" (Oesterreicher 2008: 240; cursiva original).

40 "La mayoría de la documentación romance comienza con una oración imperativa en presente de subjuntivo: sepan [en nota: $o$ conoçuda cosa sea] los que esta carta vieren, y también la práctica totalidad acaba, antes de la data, con una condicional en subjuntivo: si algún omne esta quisiere... haya la maldición... et peche, con pequeñas variantes que no hacen al caso. Todo esto pertenece a la formulística notarial o tradiciones discursivas, que se dice ahora" (Ariza Viguera 2012: 15; la cursiva no preceptiva es mía).

41 Como hace él precisamente en el trabajo del que procede esta cita.

42 Cf. también, en este sentido, las siguientes declaraciones de Pons Rodríguez (2008: 199): “coincido con Bustos (2002: 54) [...]: 'En tanto que la intertextualidad se manifiesta lingüísticamente, está sometida al cambio histórico y, por tanto, debe ser objeto de estudio también de la historia de la lengua'”. 
43 En nota: “Con ello se sitúan, en definitiva, dentro del ámbito general de las tradiciones culturales, en el sentido, por ejemplo, de Boyer (1990), quien asigna a estas tres rasgos constitutivos: el ser manifestaciones de la interacción social, el carácter repetido y el carácter psicológicamente destacado (psychological salience)" (Octavio de Toledo 2018: 118, n. 35).

${ }^{44}$ La cita completa reza: "en mi opinión, el concepto de gramaticalización está un poco devaluado por un uso 'inflacionario' en los estudios de lingüística y gramática de los últimos años. En estos trabajos, el término gramaticalización aparece usado con referencia a procesos de cambio gramatical muy variados. Como es previsible, la respuesta a la pregunta sobre el origen de la gramática, en general, y de las unidades gramaticales, en particular, tiene inevitablemente que hacer referencia a procesos muy variados y diferentes. El propio dominio de lo gramatical incluye niveles tan diferentes como los relacionados con la morfología, que también es gramática, la organización de la oración y sus argumentos, la subordinación, etc. Todos estos dominios son esencialmente gramaticales. Por ello, denominar gramaticalización a cualquier novedad surgida en cualquiera de ellos no contribuye a hacer más explícito y útil el concepto.

Al contrario, la noción de gramaticalización se ha convertido en una especie de comodín al que muchos investigadores recurren cuando quieren hacer referencia a muy variados procesos de innovación gramatical. De ahí el escepticismo con el que algunos contemplan el concepto".

45 Cf. supra la cita de Octavio de Toledo (2018: 119, n. 36), reproducida justo antes de este epígrafe de conclusiones.

46 Sobre los problemas de este tipo de acuñaciones terminológicas, cf. Kabatek (2015[2018]).

47 Cf. Kabatek (2015a: 50): "Sicherlich taucht der Begriff [der Diskurstraditionen] hier und da auf ohne jeden Bezug zu seinem ursprünglichen Wissenskontext, und das muss kritisiert werden".

48 Cf. infra n. 49.

${ }^{49} \mathrm{Al}$ defender esta postura creo estar en consonancia tanto con el espíritu de las declaraciones de Oesterreicher (2012: 231-232) reproducidas en $\S 6$, como con las visiones de Octavio de Toledo (2018) y Kabatek (2015a). A propósito de este último trabajo, dice el primero de estos dos autores lo siguiente: "Kabatek (2015a) ha insistido recientemente en la necesidad de adoptar un cambio de perspectiva metodológica por el que el investigador debería dejar momentáneamente de lado el estudio de los fenómenos lingüísticos a través del filtro de las TD singulares como entidades categorizadas (es decir, productos delimitados) para centrarse, en cambio, en las relaciones entre textos que cabe establecer a partir de la observación de los fenómenos mismos[…]. No se trata, pues, de establecer TD supuestamente caracterizadas por tales o cuales fenómenos comunes que se repiten, sino de proceder al seguimiento de dichos fenómenos a lo largo de los itinerarios textuales que trazan durante su evolución. Más que fijar las TD como producto, interesa delinear su trayectoria; y en el caso de TD complejas (como suelen serlo los textos de cierta extensión), diferenciar las diversas trayectorias de las TD menores que en él se entrecruzan y concitan. Más que las tradiciones mismas importan, por tanto, la tradicionalidad discursiva, CONCEBIDA COMO PROPIEDAD ASOCIADA A LOS FENÓMENOS, que estos van adquiriendo y perfilando conforme aumenta su repetición en determinadas constelaciones textuales" (Octavio de Toledo 2018: 121; cursiva original, la versalita es mía).

50 Cf. el texto resaltado en versalita en la cita que reproduce en la nota 49 supra.

51 El texto original alemán es el siguiente: "Die ganze Diskussion um die Diskurstraditionen krankt m.E. an einem Perspektivenproblem: Es wird von bestimmten Kategorisierungen des Wiederholten oder Wiederholbaren ausgegangen und dann gefragt, welche Diskurstradition jeweils vorliegt. Ab dem Moment jedoch, wo wir vom Terrain der Kategorien ausgehen, versperren wir uns dem Prozess des Kategorisierens selbst. Vielliecht ist es tatsächlich sinvoll, hier die von Peter Koch genannte Unterscheidung zwischen Diskurstraditionen als Entitäten und Diskurstraditionellem als prinzipiell Traditionsfähigem heranzuziehen".

52 Cf. supra n. 38. 